\title{
Rapid and Accurate Automatic Temperature Calibration of Disposable Screen-printed Heated Gold Electrodes
}

Sonivette Colón-Rodríguez, Martin Schönhoff, Juhaina Abdulkhalek, Tatiana Quiñones-Ruíz, Stephen W. Bentham, Gourav Bhowmik, Mengbing Huang, Peter Langer, Igor K. Lednev, Gerd-Uwe Flechsig

Submitted date: 21/05/2019 - Posted date: 22/05/2019

Licence: CC BY-NC-ND 4.0

Citation information: Colón-Rodríguez, Sonivette; Schönhoff, Martin; Abdulkhalek, Juhaina; Quiñones-Ruíz, Tatiana; Bentham, Stephen W.; Bhowmik, Gourav; et al. (2019): Rapid and Accurate Automatic Temperature Calibration of Disposable Screen-printed Heated Gold Electrodes. ChemRxiv. Preprint.

Joule-heated electrodes have been used to enhance electrochemical analysis. Due to such direct heating, a steep temperature gradient is created near the electrode surface. The heating device that provides the high-frequency $\mathrm{AC}$ ( $50 \mathrm{kHz}$ or more) has to be calibrated, in order to apply the desired temperature during analysis. The applied temperature of the working electrode influences both its electrical resistance and the electrochemical potential of a redox couple. Open circuit potentiometric (OCP) measurements were performed automatically with screen-printed gold loop electrodes (Au-LE), while applying $50 \mathrm{kHz}$ AC heating pulses of increasing intensity provided by a ThermaLab $\circledast A C$ generator. Potentiometric temperature calibrations were performed using $5 \mathrm{mM}$ equimolar ferri/ferrocyanide in $0.1 \mathrm{M}$ of potassium chloride at $20^{\circ} \mathrm{C}$ bulk temperature. Potential differences produced during each heat pulse were used to automatically calculate the electrode temperature using the temperature coefficient of this redox couple $(-1.6 \mathrm{mV} / \mathrm{K})$. The electrode resistance values at each heating pulse were obtained by measuring the heating voltage and heating current. The automatic temperature calibration experiments with five Au-LEs were shown to be highly reproducible and precise, with an RSD for the temperature of $0.24 \%$ and $4 \%$ for resistance. The average margin error of OCP temperatures were $\pm 0.66 \mathrm{~K}$ at a $95 \%$ confidence level. The temperature coefficient (a) of electrical resistivity of the screen-printed gold layers was found to be $0.0025{ }^{\circ} \mathrm{C}^{-1}$, which is $27 \%$ lower than the theoretical value for gold metal. These findings were confirmed by DC resistance measurements using a potentiostat. Comparing the OCP temperature with the resistivity method, the temperature difference was about $0.94{ }^{\circ} \mathrm{C}(2.8 \%)$. Both methods enable quick, reproducible and accurate temperature calibration for disposable Au-LE, which were also used for trace mercury detection in lake water samples

File list (2) 


\title{
Rapid and Accurate Automatic Temperature Calibration of Disposable Screen-printed Heated Gold Electrodes
}

Sonivette Colón-Rodríguez ${ }^{\mathrm{a}}$, Martin Schönhoff ${ }^{\mathrm{b}}$, Juhaina Abdulkhalek ${ }^{\mathrm{c}}$, Tatiana Quiñones-Ruíz ${ }^{a}$, Stephen W. Bentham ${ }^{d}$, Gourav Bhowmike, Mengbing Huang ${ }^{\mathrm{e}}$, Peter Langer ${ }^{c}$, Igor K. Lednev ${ }^{a}$, Gerd-Uwe Flechsig a,b,d,f*,

a) University at Albany, SUNY, Dept. of Chemistry, 1400 Washington Ave, Albany, NY 12222, United States

b) Gensoric GmbH, G.-Hauptmann-Str. 23, 18055 Rostock, Germany

c) University of Rostock, Dept. of Chemistry, A.-Einstein-Str. 3a, 18059 Rostock, Germany

d) Manchester Metropolitan University, School of Science and the Environment, M1 5GD, Manchester, United Kingdom

e) Colleges of Nanoscale Science and Engineering, SUNY Polytechnic Institute, Albany, NY, 12203, United States

f) Coburg University of Applied Sciences and Arts, Faculty of Applied Natural Sciences, Friedrich-Streib-Str. 2, 96450 Coburg, Germany

${ }^{*}$ Corresponding author: gerd-uwe.flechsig@hs-coburg.de

\begin{abstract}
Joule-heated electrodes have been used to enhance electrochemical analysis. Due to such direct heating, a steep temperature gradient is created near the electrode surface. The heating device that provides the high-frequency AC (50 kHz or more) has to be calibrated, in order to apply the desired temperature during analysis. The applied temperature of the working electrode influences both its electrical resistance and the electrochemical potential of a redox couple. Open circuit potentiometric (OCP) measurements were performed automatically with screen-printed gold loop electrodes (Au-LE), while applying $50 \mathrm{kHz}$ AC heating pulses of increasing intensity provided by a ThermaLab® AC generator. Potentiometric temperature calibrations were performed using $5 \mathrm{mM}$ equimolar ferri/ferrocyanide in $0.1 \mathrm{M}$ of potassium chloride at $20^{\circ} \mathrm{C}$ bulk temperature. Potential differences produced during each heat pulse were used to automatically calculate the electrode temperature using the
\end{abstract}


temperature coefficient of this redox couple (-1.6 mV/K). The electrode resistance values at each heating pulse were obtained by measuring the heating voltage and heating current. The automatic temperature calibration experiments with five Au-LEs were shown to be highly reproducible and precise, with an RSD for the temperature of $0.24 \%$ and $4 \%$ for resistance. The average margin error of OCP temperatures were $\pm 0.66 \mathrm{~K}$ at a $95 \%$ confidence level. The temperature coefficient $(\alpha)$ of electrical resistivity of the screen-printed gold layers was found to be $0.0025^{\circ} \mathrm{C}^{-1}$, which is $27 \%$ lower than the theoretical value for gold metal. These findings were confirmed by DC resistance measurements using a potentiostat. Comparing the OCP temperature with the resistivity method, the temperature difference was about $0.94{ }^{\circ} \mathrm{C}(2.8 \%)$. Both methods enable quick, reproducible and accurate temperature calibration for disposable Au-LE, which were also used for trace mercury detection in lake water samples.

Keywords: Directly heated electrode; open circuit potentiometry; resistivity; automatic temperature calibration; gold electrode; mercury determination

\section{Introduction}

Heated electrodes have been used increasingly to enhance electrochemical analysis or for fundamental thermodynamic and kinetic studies of redox systems $[1,2,3,4,5]$. Due to direct electrical heating, a temperature gradient inside the bulk solution is created near the electrode surface. Thus, high temperature is only applied at the location, where electrochemistry takes place, i.e the electrode surface. The temperature of the bulk electrolyte can remain constant at room temperature or even below.

Heated electrodes have been applied for various chemical sensor applications. Stripping determinations of arsenic $(\mathrm{V})$ by direct electrochemical reduction was conducted at a gold wire electrode [6]. Lead was determined by cathodic stripping of deposited $\mathrm{PbO}_{2}$ at platinum micro-wire electrodes [7]. Mercury(II) [8], copper(II) 
and arsenic(III) traces have been determined on gold micro-wire electrodes [9]. The latter article reported that the micro-stirring effect at a thin (25-micron diameter) gold wire resulted in a better signal enhancement compared with the use of a rotating disk electrode (RDE). Another focus of that article was a study of temperature effects upon deposition and multiple stripping scans of $\mathrm{Hg}, \mathrm{Cu}$, and As. Heated mercury film electrodes based on iridium and screen-printed carbon have been applied for cadmium and lead analysis $[10,11]$.

Beside micro-wires, also glassy carbon [12], pencil $[13,14,15]$ electrodes and even carbon paste electrodes have been joule-heated directly [16,17].

In all of these cases, the temperature calibration plays a crucial role, i.e. it is essential to find the function between heating power (heating voltage or heating current) and electrode temperature in order to apply any desired temperature value. Most groups that studied directly and indirectly heated electrodes performed temperature calibrations based on ferro/ferricyanide as a redox couple for chronopotentiometry. This approach is therefore widely accepted $[18,19,20]$. A Pt100 resistance thermometer or a thermo-element cannot be attached to the directly heated electrode, because it would disturb the measurements, and secondly, it would most probably not display the correct temperature value due to problems with heat transfer and temperature gradients. Another alternative approach for directly heated electrodes is based on precise resistance measurements. For this "resistance method", introduced by Gabrielli et al. [21], the heated electrode serves as its own resistance thermometer. Both the heating current through and the voltage drop across the heated electrode are being measured. The resistance is then calculated according to Ohm's law. Since the temperature coefficient of electric resistivity is well-known for most metals, the temperature can be calculated using equation (1),

$R=R_{20}\left[1+\alpha\left(\theta-20^{\circ} \mathrm{C}\right)\right]$

where $R$ is the resistance of the heated electrode at the temperature $\theta, \alpha$ is the temperature coefficient of the electrical resistivity, and $R_{20}$ is the electrode resistance 
at $20^{\circ} \mathrm{C}$. This method works well with micro-wire electrodes, because the geometry is very well defined and reproducible. The applied temperature of the electrode surface depends linearly on the heating power $P$, i.e. on electrode resistance $R$ and the square of the current I of the (AC) heating pulses as described by eq. (2).

$P=R I^{2}$

The second method relies on the temperature coefficient of the standard potential of a proper redox couple, in particular ferro/ferricyanide. According to the Nernst equation (3), with equimolar concentrations, we only have to deal with the temperature dependence of the standard potential or the standard entropy, respectively. The entire logarithmic term with gas constant $R$, temperature $T$, number of transferred electrons $\mathrm{n}$, and Faraday constant $\mathrm{F}$ becomes zero.

$E=E^{o}+\frac{R T}{n F} \ln \frac{\left[\mathrm{Fe}(\mathrm{CN})_{6}^{3-}\right]}{\left[\mathrm{Fe}(\mathrm{CN})_{6}^{4-}\right]}$

Open circuit potentiometry (OCP) can be used to measure the potential shift, if both components of the redox couple are present at equimolar concentrations. By voltammetric determination of the half-wave potential it is possible, to work with only one such component [22].

Until now, heated electrodes of any kind have been used many times after manufacturing them and performing a single temperature calibration. In case of adjusting the heating current with micro-wire electrodes, it has been expected that the same temperature difference is achieved each time a certain heating current is applied, no matter how long the wire electrode is. It is, however, tedious to perform the OCP procedure in case of disposable sensor chips such as screen-printed electrodes. We have been using screen-printed gold-loop electrodes (Au-LE) once before to study the deposition of copper by means of time-of-flight secondary ion mass spectrometry (ToF-SIMS) [23]. That study revealed that there may be deep 
pores in the sintered gold layer that can retain small volumes of electrolyte.

While OCP with ferro/ferricyanide has been used very successfully in aqueous electrolytes, it has turned out to be difficult in non-aqueous solutions because proper redox couples are hard to find [24]. Such a redox couple must be available and stable in both conjugate forms, soluble, and provide a sufficient temperature coefficient of the standard potential.

Here, we introduce an accurate automatic temperature calibration approach based on potentiometry with ferro/ferricyanide. The new method was compared with resistivity-based measurements. Accuracy of the temperature of new Au-LE was compared and evaluated. The question was whether or not such electrodes are sufficiently alike enabling to apply one temperature calibration function for all sensors of a batch. Alternatively, a simple correction factor obtainable by a single resistance measurement could have been sufficient to apply one temperature calibration for all sensors of a batch. It turned out that not even the temperature coefficient of the resistivity for gold was applicable and constant for all the screen-printed electrodes. Therefore, we have developed a quick 10-min automatic calibration method that allows accuracy of better than $0.5 \mathrm{~K}$. The automatic temperature calibration was then tested by analyzing mercury(II) in water samples allowing us to apply $60{ }^{\circ} \mathrm{C}$ and $70^{\circ} \mathrm{C}$, electrode temperature, during the deposition step.

\section{Experimental}

\subsection{Instrumentation}

Directly heated Au-LE sensor chips according to our design were screen-printed and delivered by DropSens (Spain) and used as working electrodes (WE). The reference electrode $(\mathrm{RE})$ was a $\mathrm{Ag} / \mathrm{AgCl}(3 \mathrm{M} \mathrm{KCl})$ (Metrohm-Autolab, Switzerland). All measurements were performed inside a Faraday cage. All temperature calibrations were performed by means of a ThermaLab (Gensoric GmbH, Rostock, Germany) 
equipped with EmStat3 potentiostat (PalmSens BV, The Netherlands) and a $50 \mathrm{kHz}$ AC generator. Open-circuit potentiometry was performed for the temperature calibration using ThermaLab Tool software v.0.952 (Gensoric). A multimeter 570ATrueRMS (Extech Instruments) was used to measure the heating voltage drop across the WE. Heating $A C$ values were obtained by measuring the voltage drop across a $1 \Omega$ serial precision resistor, purchased from Mouser Electronics $₫$ (Texas, USA), using a digital oscilloscope from Tectronic (30 MHz-500 MS/s). A differential oscilloscope probe GE8109 (1x attenuation) from Elditest Electronic was used to connect the digital oscilloscope to the $1 \Omega$ precision resistor in the circuit.

SEM images were generated using a JEOL Ltd JSM-5600LV scanning electron microscope together with SEM User Interface (Version 3.02) software. Parameters included a working distance of $10 \mathrm{~mm}$, with a spot-size of $30+/-5$, with an electron beam intensity of $10 \mathrm{keV}$.

EDX analysis was performed via the INCA $x$-ray microanalysis system with a INCA $x$-sight $\mathrm{Si}(\mathrm{Li})$ EDS detector probe (model No. 7388 ) and INCA s-stream pulse processor (from Oxford Instruments), incorporating the INCA Suite Software (Version 3.04). EDX analysis was performed with the above parameters excluding a working distance of $20 \mathrm{~mm}$ and a spot-size ranging from 50-80 depending on the image

Atomic force microscopy (AFM) images were obtained using an AIST-NT Reflection AFM (Novato, CA, USA) in combination with A OMEGA software (version 3.5.61). AFM images were taken using AC tapping mode with a single-crystal silicon cantilever. The cantilever manufacture frequency was $300 \mathrm{kHz}$ at a force constant of $40 \mathrm{~N} / \mathrm{m}$. The conical tip height was $15 \mu \mathrm{m}$ with $\sim 8 \mathrm{~nm}$ radius.

Ion beam analysis was performed using Rutherford Backscattering Spectrometry (RBS) to determine the gold layer thickness in combination of XRUMP software. RBS analysis was performed using a RPEA 4.0 Dynamitron particle accelerator $\left({ }^{4} \mathrm{He}\right.$ gas, with charge 1 and molecular state 1 ) at a high energy of $2.00 \mathrm{MeV}$. 


\subsection{Chemicals:}

All chemicals used for the experiments were received from certified manufacturers and were of analytical grade. Sulfuric acid $(0.5 \mathrm{M})$ was used as supporting electrolyte in all cyclic voltammetric cleaning procedures. All solutions were diluted as needed using distilled water. Automatic temperature calibration of each directly heated AuLE chip was performed as described below by open circuit potentiometry in $5 \mathrm{mM}$ equimolar ferri/ferrocyanide solution containing $0.1 \mathrm{M} \mathrm{KCl}$ as supporting electrolyte. Sulfuric acid was provided by Agros Organic (Belgium). Potassium hexacyanoferrate(III) was provided by Chem-Impex (Illinois, USA). Potassium hexacyanoferrate(II) trihydrate and potassium chloride were provided by SigmaAldrich (Germany). All solutions were prepared using distilled water from a Barnstead Mega-Pure ${ }^{\circledR}$ System ACS MP-11A.

\subsection{Electrochemical cleaning of the gold loop electrode}

Electrochemical cleaning was performed in a three-electrode electrochemical cell containing $20 \mathrm{~mL}$ of $0.5 \mathrm{M} \mathrm{H}_{2} \mathrm{SO}_{4}$ as supporting electrolyte. The Au-LE were scanned using cyclic voltammetry at a starting potential of $-0.2 \mathrm{~V}$, 1st vertex potential $1.5 \mathrm{~V}$ and $2 \mathrm{nd}$ vertex potential $-0.2 \mathrm{~V}$. A single cleaning step would last for a duration of 25 cycles and cleaning was repeated until changes in sequential voltammograms were deemed negligible or whether the voltammogram was comparable to a reference voltammogram. An approximate active area of $0.326 \mathrm{~cm}^{2}$ of the Au-LE was calculated from the reduction peak and the conversion factor $480 \mu \mathrm{C} / \mathrm{cm}^{2}$ [25]. The Au-LE had a geometric surface area of $0.0924 \mathrm{~cm}^{2}$. 


\subsection{Automatic potentiometric temperature calibration}

The automatic temperature calibration was performed by open-circuit potentiometric (OCP) measurements while applying five $A C$ heating pulses of increasing intensity. The heating generator ThermaLab allowed to adjust "power steps", an arbitrary unit. The electric resistance of the heated Au-LE was calculated for each applied power step by measuring both heating current and heating voltage during the automatic temperature calibration. The OCP calibration solution $(5 \mathrm{mM}$ ferri/ferro cyanide in $0.1 \mathrm{M} \mathrm{KCl}$ ) was maintained at $20{ }^{\circ} \mathrm{C}$ during the automatic temperature calibration using an ANOVA circulating water bath.

\subsection{Temperature calibration based on measurements of electric resistivity}

The digital oscilloscope was used to measure the true RMS voltage drop (V) across a $1 \Omega$ precision resistor connected in series with the Au-LE. This voltage drop was then used to calculate the heating current in the circuit using Ohm's law (eq. 4), $\mathrm{I}=\mathrm{U} / \mathrm{R}$

where $\mathrm{I}$ is the heating current, and $\mathrm{U}$ the voltage drop across the resistor $\mathrm{R}$. The heating voltage (i.e. the voltage drop across the heated electrode) was measured in parallel to the Au-LE using the TrueRMS multimeter (Fig. 4B).

\subsection{Stripping-voltammetry of mercury in water samples}

Mercury trace determination was performed using square wave voltammetry (SWV) in water samples containing $0.1 \mathrm{M}$ sulfuric acid and $0.01 \mathrm{M}$ hydrochloric acid as supporting electrolyte. A glassy carbon electrode and a $\mathrm{Ag} / \mathrm{AgCl}$ in $3 \mathrm{M} \mathrm{KCl}$ were used as counter and reference electrode respectively. The working electrode, Au$\mathrm{LE}$, was chemically cleaned before each analysis with $0.5 \mathrm{M}$ sulfuric acid by cyclic voltammetry. A $0.7 \mathrm{~V}$ was applied as a conditioning potential for $60 \mathrm{~s}$ and a 
deposition potential of $0.2 \mathrm{~V}$ for $120 \mathrm{~s}$ and an equilibrium time of $5 \mathrm{~s}$ before SWV measurements. Stripping measurements were performed from $0.2 \mathrm{~V}$ to $0.8 \mathrm{~V}$ with a step potential of $3 \mathrm{mV}$, an amplitude of $30 \mathrm{mV}$ and a frequency of $20 \mathrm{~Hz}$. All analyses were performed in presences of dissolved oxygen. The real water sample was collected from Black River Pond (Cherry Plain State Park, NY at $42^{\circ} 37^{\prime} 08^{\prime \prime} \mathrm{N}$ and $73^{\circ} 24^{\prime} 41^{\prime \prime} \mathrm{W}$ ), filtrated using a filter system of $0.45 \mu \mathrm{m}$ PES from CELLTREAT ${ }^{\circledR}$. Filtrated water sample was then acidified with $69 \%$ nitric acid and stored at $4{ }^{\circ} \mathrm{C}$. UV digestion treatment was conducted in quartz tubes containing $30 \mathrm{~mL}$ of the water sample containing $40 \mu \mathrm{L}$ of $30 \%$ hydrogen peroxide. The quartz tube was sealed and irradiated for one hour with UV light.

\section{Results and Discussion}

\subsection{Evaluation of gold electrode geometry and composition}

Figure 1 displays topographical features of a new Au-LE after electrochemical cleaning by cyclic voltammetry in $0.5 \mathrm{M}$ sulfuric acid. It was revealed through a point and ID function on the EDX, that the cluster-like protrusions on the Au surface were identified to be $A u$ (Table 1). EDX analysis of the electrode surface further revealed that elements $\mathrm{C}, \mathrm{O}$ and $\mathrm{Al}$ were present, including $\mathrm{Au}$. Features shaped like "nodules" were suggested to be $95.83 \% \mathrm{Au}$ and $4.17 \% \mathrm{C}$. It is highly unlikely that any carbon was incorporated in this structure and was most likely some unseen organic matter on the surface of the structure (carbon was found to be present for almost all gold surfaces analyzed and was interpreted the same way).

Figure 1 resolved thin black networks appearing largely throughout the surfaces. Such networks were deduced to be deep crevices or canyons in the Au surface. Analysis revealed the presence of aluminum and oxygen at $4.75 \%$ and $2.91 \%$ weight percentages respectively. Prior knowledge that the gold film was screen printed onto an alumina substrate, in combination with the EDX data that was obtained, support 
that it is highly likely that such crevices are deep holes in the Au surface that reveal the alumina substrate. Reasons to why these channels are present are yet to be found, however they may be present due to damage.

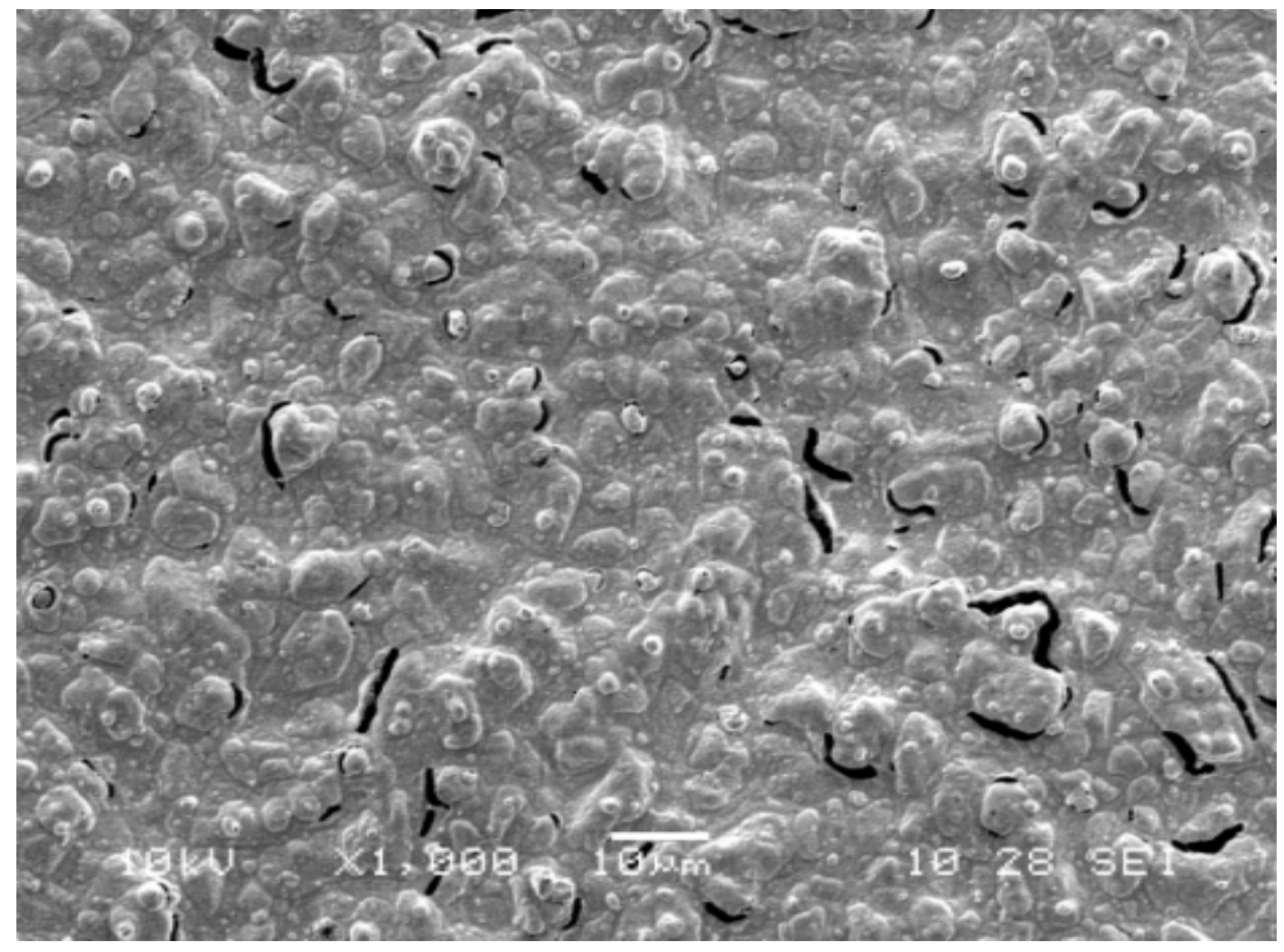

Figure 1. SEM image of a Au Surface at x1000 magnification after electrochemical cleaning in $0.5 \mathrm{M}$ $\mathrm{H}_{2} \mathrm{SO}_{4}$ using Cyclic Voltammetry; for 25 scans using a scan rate of $0.01 \mathrm{~V} / \mathrm{s}$ between 0 and $1.4 \mathrm{~V}$.

Area scans of two seemingly identical gold loop electrodes revealed similar quantities of $\mathrm{C}, \mathrm{O}$ and $\mathrm{Au}$ (Table 1). However, the electrode surfaces are not of identical composition. 
Table 1. Tabulated EDX results comparing electrodes $A$ and $B$, after electrochemical cleaning in in $0.5 \mathrm{M} \mathrm{H}_{2} \mathrm{SO}_{4}$ using Cyclic Voltammetry; for 25 scans using a scan rate of $0.01 \mathrm{~V} / \mathrm{s}$ and results allocated to the dark networks and nodule respectively.

\begin{tabular}{|c|c|c|c|c|c|c|c|c|}
\hline \multirow{3}{*}{ Element } & \multicolumn{9}{|c|}{ Electrodes A and B. Conditioned. } \\
\cline { 2 - 9 } & \multicolumn{3}{|c|}{ A } & \multicolumn{2}{c|}{ B } & \multicolumn{2}{c|}{ Dark network } & \multicolumn{2}{c|}{ Nodule } \\
\cline { 2 - 9 } & $\begin{array}{c}\text { Weight } \\
\%\end{array}$ & $\begin{array}{c}\text { Atomic } \\
\%\end{array}$ & $\begin{array}{c}\text { Weight } \\
\text { \% }\end{array}$ & $\begin{array}{c}\text { Atomic } \\
\%\end{array}$ & $\begin{array}{c}\text { Weight } \\
\%\end{array}$ & $\begin{array}{c}\text { Atomic } \\
\%\end{array}$ & $\begin{array}{c}\text { Weight } \\
\%\end{array}$ & $\begin{array}{c}\text { Atomic } \\
\%\end{array}$ \\
\hline C & 2.90 & 32.06 & 1.93 & 23.28 & 2.87 & 22.73 & 4.17 & 41.62 \\
\hline O & 0.33 & 2.74 & 0.39 & 3.55 & 2.91 & 17.28 & - & - \\
\hline Al & - & - & 1.38 & 1.38 & 4.75 & 16.77 & - & - \\
\hline Au & 96.77 & 65.19 & 97.43 & 71.79 & 89.47 & 43.22 & 95.83 & 58.38 \\
\hline
\end{tabular}

Firstly, there was no appearance of $\mathrm{Al}$ on the spectra for electrode $\mathrm{A}$, therefore it must be assumed that the occurrence of such canyons on this electrode is considerably less than on electrode B. Additionally, weight percentages of gold are $96.77 \%$ and $97.43 \%$ respectively for electrodes $A$ and $B$. This can be interpreted in one of two ways: small quantities of gold oxide have formed over time on the electrode surfaces or different amounts of organic film remain present on the surface after electrochemical cleaning altering the percentages obtained. The latter is more likely, as larger differences in $\mathrm{C}$ weight percentages can be observed $(2.90 \%$ and $1.93 \%$ for electrodes $A$ and $B$ respectively).

\subsection{Atomic Force Microscopy and Rutherford Back-scattering Spectroscopy}

AFM images were taken of the Au-LE sensor chip at the edge of the screen-printed gold layer in order to investigate the thickness of the gold layer. To differentiate the gold layer from the bare substrate surface, images were taken of each surface individually and later at the "boundary" between the bare ceramic substrate $\left(\mathrm{Al}_{2} \mathrm{O}_{3}\right)$ and the gold layer. Topographic and phase mode images were recorded simultaneously in tapping mode with a resolution of $500 \times 500$ pixels. Individual surface images were recorded in a $25 \times 25 \mu \mathrm{m}^{2}$ section (Fig. 2) at $0.3 \mathrm{~Hz}$ scanning frequency. The rim of the gold layer was recorded in a $50 \times 50 \mu \mathrm{m}^{2}$ section at a 
frequency of $0.2 \mathrm{~Hz}$ (Fig. 3).

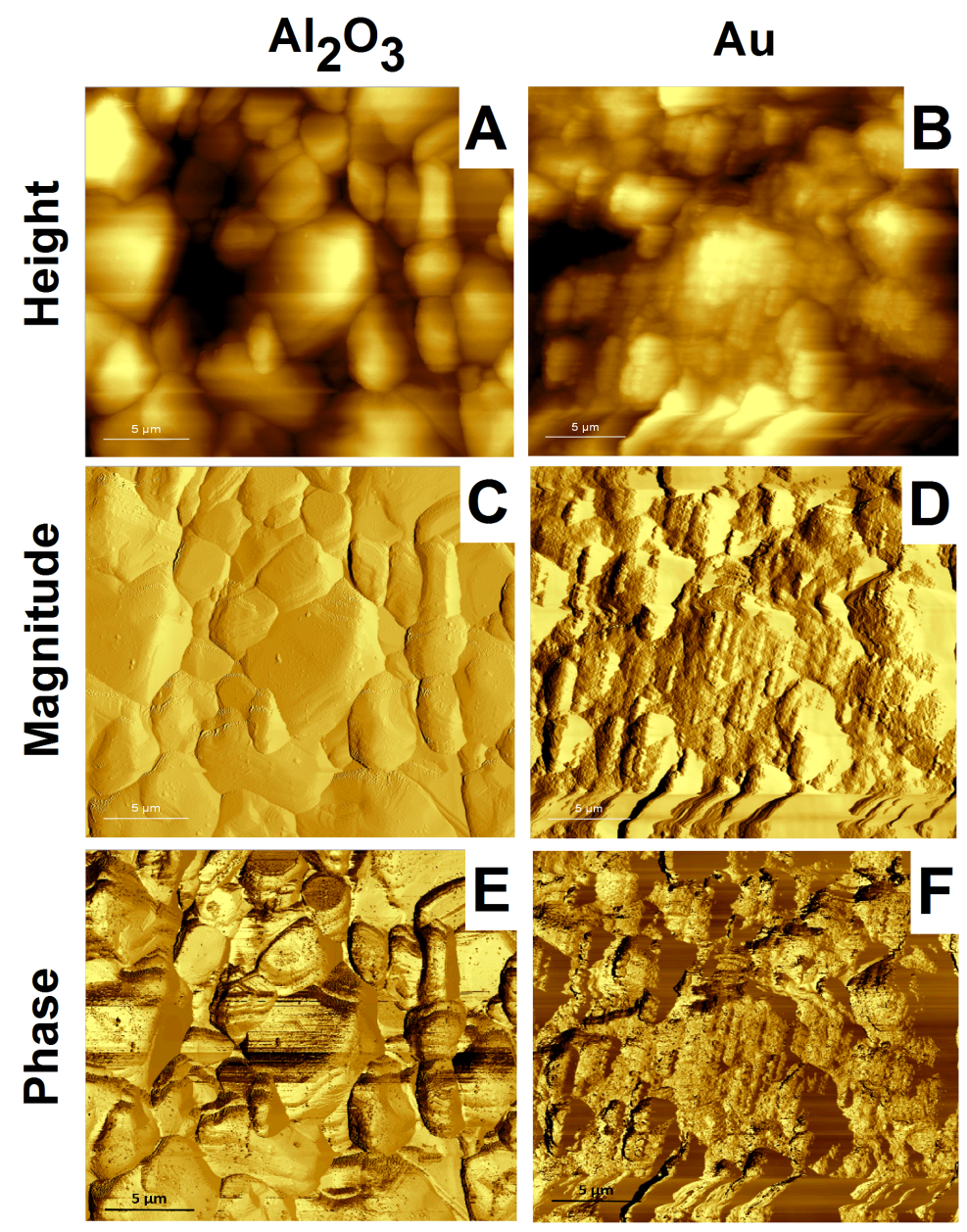

Figure 2. AFM images of Au-LE of $\mathrm{Al}_{2} \mathrm{O}_{3}$ substrate and gold $(\mathrm{Au})$ layers in a $25 \times 25 \mu \mathrm{m}$ section at 0.3 $\mathrm{Hz}$ with a resolution of $500 \times 500$ pixels in different AFM modes: height $(A, B)$, magnitude $(C, D)$ and phase $(E, F)$.

The gold surface was characterized by a much rougher appearance in comparison with the bare alumina surface. The thickness of the gold layer was determined by using the AFM image that covered the rim between the surfaces of both ceramic substrate and gold layer (Fig. 3) and measuring the height (z-scale) in different spots of this "boundary". The average thickness was calculated to be $1.8 \mu \mathrm{m}$.

Measurements by RBS revealed a gold layer of $600 \mathrm{~nm}$ thickness in average 
(Fig. S1). The peculiar shape of the RBS spectrum for the gold layer suggests that its thickness is not very uniform across the electrode surface. Such non-uniformity may be caused by the formation of porous structures during gold thin film deposition or by the possibility of pre-existing micron scale features at the electrode surface.
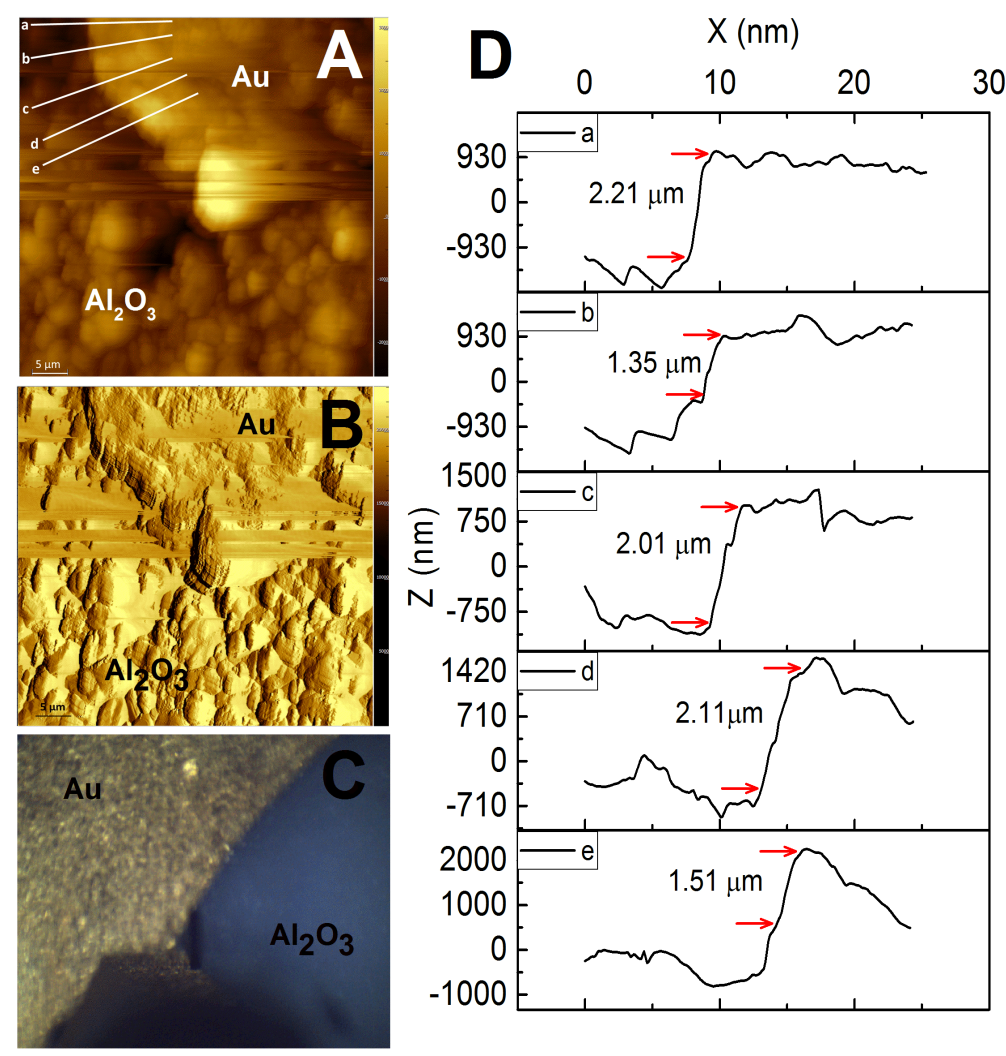

Figure 3. (A) AFM height mode and (B) magnitude mode images of Au-LE of the "boundary" between gold layer and ceramic substrate $\mathrm{Al}_{2} \mathrm{O}_{3}$, of a $50 \times 50 \mu \mathrm{m}$ section at $0.2 \mathrm{~Hz}$ and $500 \times 500$ pixel resolution, (C) optical microscopy image of the boundary, and (D) thickness measurements of the gold layer (Zscale) of selected areas, white lines of $25 \mathrm{~nm}$ in the height mode image, (A).

Measurements with a micrometer dial gauge did not indicate any thicker gold layers, in fact, the pointer of the dial gauge did not move significantly across the scale (smallest tick 1 micron).

These results indicate that the screen-printed and tempered gold ink formed a very 
thin gold layer on top of considerably larger topologic features of the alumina substrate.

\subsection{Open-Circuit Potentiometry}

Figure 4A displays the OC potentiogram of an Au-LE sensor with five increasing heating pulses, which result in the increase of the electrode temperature.

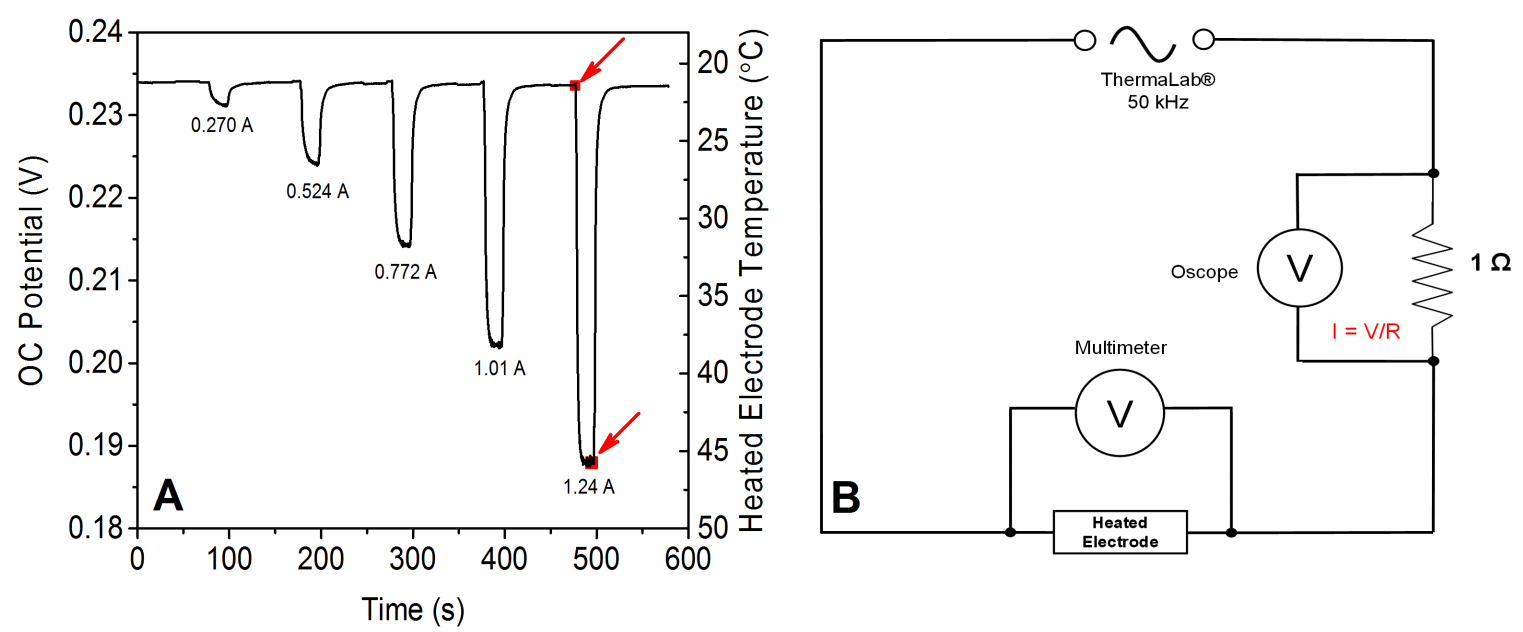

Figure 4. (A) Open-circuit potentiogram of a Au-LE for temperature calibration averaging 5 points before the beginning and before the end of each pulse (as indicated by red arrows) as an automatic potential readout. (B) Circuit scheme of resistance measurement during temperature calibration.

Individual temperature calibrations were performed with five Au-LE, each with five repetitions (Table S1). We developed this new and quick automated temperature calibration procedure to improve reproducibility. Figure 5 illustrates the results of this automatic temperature calibration based on five different heating power settings. This technique called "Temperature Pulse Potentiometry" (TPP) as reported earlier $[26,27,28]$ was performed manually until now. Figure $5 \mathrm{~A}$ displays calculated potential 

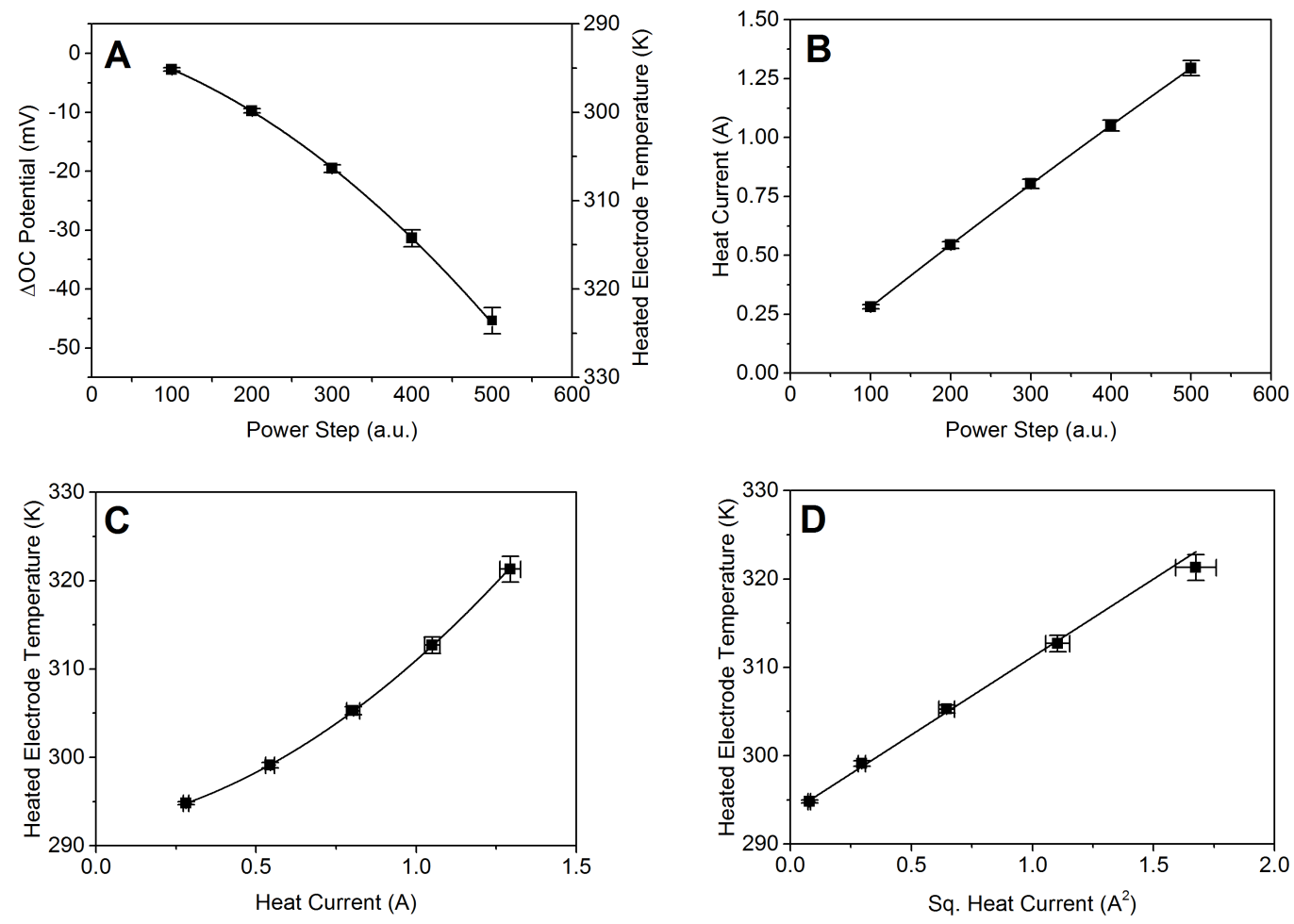

Figure 5. (A) Automatic Temperature Calibration with five heating power steps based on open-circuit potentiometry of five Au-LE using potential difference (vertical error bars) and calculated heated electrode temperature using the temperature coefficient of the redox couple (-1.60 mV/K). Quadratic relationship between $(A)$ power step and $(C)$ heating current with the heated electrode temperature and $(B)$ between the heating current and the power step. (D) Linear fit of the electrode temperature against the square heat current.

differences between the points before the beginning and the end of each heat pulse. These potential differences were converted into temperature differences using the temperature coefficient $-1.60 \mathrm{mV} / \mathrm{K}$ of ferri/ferrocyanide. The temperature calibration plot required a quadratic function as has been discussed earlier by Zerihun and Gründler [29]. Briefly, the reason can be found in the quadratic relationship between electric current and electric power. After the calibration and providing the ambient temperature value, the software calculates and applies the "proper power step" by means of the quadratic fit function, according to the desired electrode temperature. The automatic temperature calibration is very reproducible as demonstrated in Fig. 5 
between the five electrodes, but also within the same chip. Table S2 lists the standard deviation and relative standard deviation between five electrodes. As the temperature increases, the deviation between electrodes increases as well. Occasionally that happened for one and the same electrode. Between the five AuLE the lowest temperature deviation was at the lowest power step with a std. dev. of $0.18 \mathrm{~K}$ and RSD of $0.06 \%$, due to the low electrode temperature. On the other hand, the highest temperature deviation was at the highest heat pulse with the std. dev. of $1.46 \mathrm{~K}$ and RSD of $0.45 \%$. Deviation of electrode temperature for one and the same electrode varies from electrode to electrode. The lowest RSD at the lowest power step was $0.04 \%$ (Au-LE 2) and the highest $0.23 \%$ (Au-LE 5). For the highest power step the lowest RSD was $0.08 \%$ (Au-LE 1) and the highest 0.94\% (Au-LE 4).
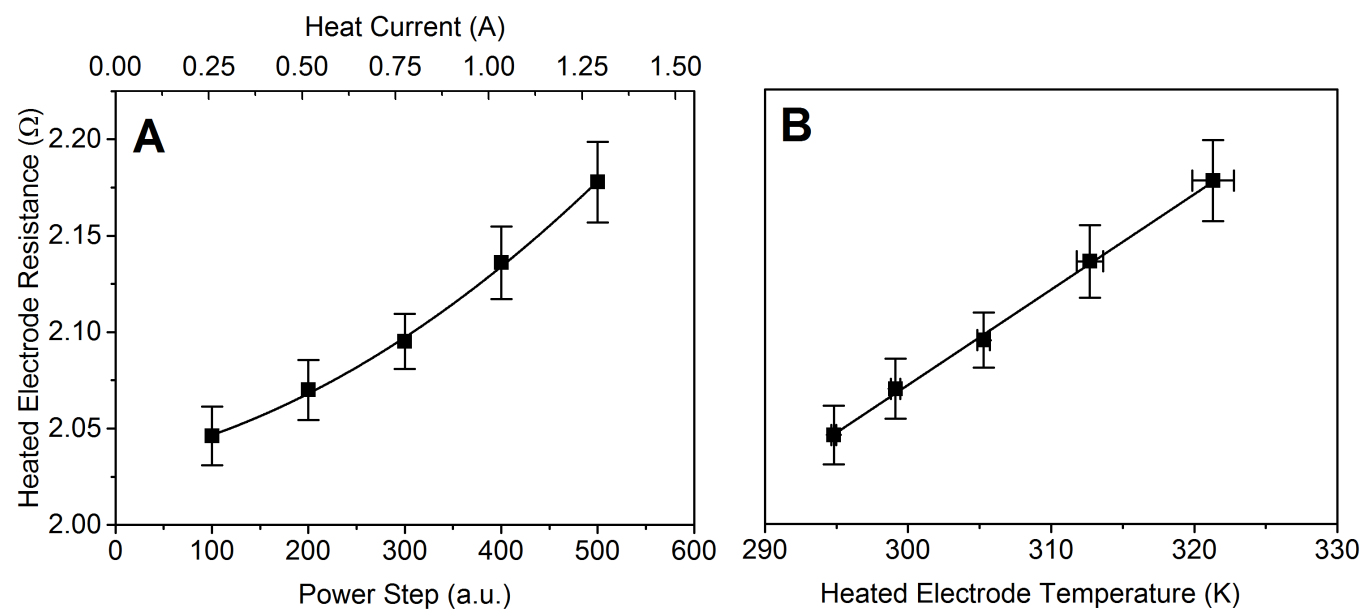

Figure 6. (A) Resistance measurements of four Au-LE at five heating power steps during temperature calibration. (B) Directly heated electrode resistance at calculated heated electrode temperature of four Au-LE. Statistics after Q-test for heated electrode resistance measurements. Resistance values

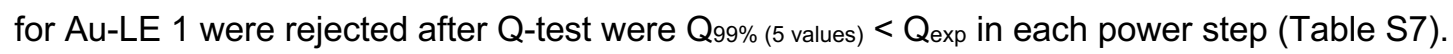

The heated electrode resistance was determined as previously described using equation 4 and presented in Fig. 6. The temperature coefficient ( $\alpha$ ) was obtained from the resistance and temperature calibration plot and presented in Table S3. The electric resistivity was calculated for each heat pulse by its temperature dependence using equation 5 , (Table S4), 
$\rho=\rho_{20}\left[1+\alpha\left(\theta-20^{\circ} \mathrm{C}\right)\right]$

where $\rho$ represent the resistivity at a particular temperature $\theta, \rho_{20}$ is the resistivity of gold metal at $20^{\circ} \mathrm{C}\left(2.44 \times 10^{-8} \Omega \mathrm{m}\right)$, and $\alpha$ is the temperature coefficient of the resistivity of gold at $20{ }^{\circ} \mathrm{C}$ obtained from experimental data. The temperature coefficient of the heated electrodes was calculated in each temperature calibration and compared to the literature value $\left(0.0034{ }^{\circ} \mathrm{C}^{-1}\right)[30]$.
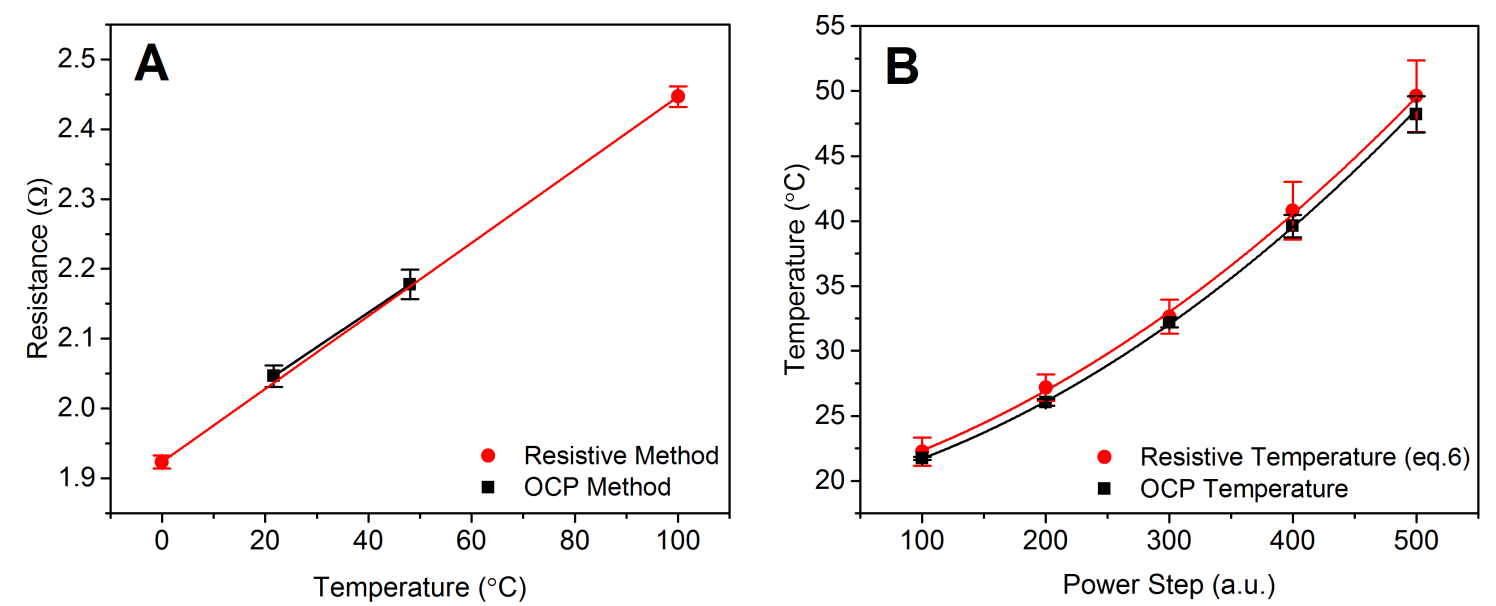

Figure 7. (A) Two-point temperature calibration of four Au-LE by OC potentiometry and the resistivity method. The measured resistance for the resistivity method was corrected by subtracting the resistance-offset contributed by the multimeter connectors. Electrode Au-LE 1 was rejected as an outlier after $Q$ test (Table S7). (B) Electrode temperature comparison from open-circuit potentiometry of five electrodes and calculated temperature from equation 6 , using the heated electrode resistance at each power step and the temperature coefficient $\alpha$, from each temperature calibration method.

\subsection{Two-point calibration with the electrode as a resistive thermometer}

Figure 7A illustrates the two-point temperature calibration of four screen-printed electrodes comparing two different temperature calibrations: open-circuit potentiometry and electrode as a resistance thermometer. The OCP heated 
electrode temperature and resistance were obtained from the automatic temperature calibration. The resistivity method of temperature calibration was performed by measuring the resistance of the Au-LE at two different temperatures of a water bath. An ice bath was used for the first point in the calibration at $0{ }^{\circ} \mathrm{C}$, and the second point at $100{ }^{\circ} \mathrm{C}$ was measured using boiling water. The temperature coefficient of resistivity of the screen-printed gold layer obtained by the resistance method was $0.00237^{\circ} \mathrm{C}^{-1}$ with a RSD of $1.72 \%$. This temperature coefficient is $30.4 \%$ lower than the literature value for gold. The value obtained by the resistance method was $2.62 \%$ lower than the one based on OCP measurements $\left(0.00243^{\circ} \mathrm{C}^{-1}\right)$. This temperature coefficient was used with eq. 6 to recalculate the electrode temperature. In Fig. 7B the temperatures were obtained by OCP method (black) and calculated using equation 6 and $\alpha$ values from the resistivity method (red).

Using the resistance of the heated electrode (Fig. 6) during the OCP and the two $\alpha$ values, from automatic temperature calibration and resistance thermometer technique, the electrode temperature was calculated for each heating pulse (Fig. 7B). These temperatures were calculated using rearranged equation (1),

$\theta=20^{\circ} \mathrm{C}+\frac{\mathrm{R}-\mathrm{R}_{20}}{\alpha R_{20}}$

where $\theta$ is the electrode temperature at a particular resistance $R$, whereas $R_{20}$ is the resistance at $20^{\circ} \mathrm{C}$, and $\alpha$ is the temperature coefficient of the resistance $\left({ }^{\circ} \mathrm{C}^{-1}\right)$.

The determination of a common conversion factor could minimize the time of the temperature calibration considerably by performing a two-point calibration for each single electrode chip. The Au-LE were dipped in both boiling water and ice bath and the two regarding resistance values was measured with a TrueRMS multimeter. Dixon's $Q$ test was performed to test for outliers (Table S7). Au-LE 1 was rejected for the resistance measurements (Fig. 6 and 7) with a 99\% confidence level after the $\mathrm{Q}$ test. The $\mathrm{Q}_{\exp }$ average value for Au-LE resistance was 0.872 (Q99\% for five sample is 0.821$)$. 
The $\alpha$ value was calculated and presented in Table S6. These $\alpha$ values were then used to calculate the electrode temperature using equation 6 and compared with the temperature obtained from the automatic temperature calibration by $\mathrm{OC}$ potentiometry. It was observed that most of the time the calculated electrode temperature, with the a value from the resistance method, was slightly higher than the electrode temperature from the OC potentiometry (Fig. 7B).

Figure 6 illustrates the increase of the electrode resistance as the power step (A) and electrode temperature $(B)$ increases. As mentioned before, the relation between the resistance and the power step, as well as with the heating current, both showed a quadratic relation. On the other hand, a linear relation was observed between electrode resistance and the electrode temperature. The experimental temperature coefficient $\alpha\left({ }^{\circ} \mathrm{C}^{-1}\right)$, of each Au-LE was calculated from the slope of linear fit of the temperature calibration plot (Fig. 6B) and divided by the electrode resistance at $20{ }^{\circ} \mathrm{C}$. The $\alpha$ value $\left({ }^{\circ} \mathrm{C}^{-1}\right)$ was also obtained from an independent temperature calibration by controlling water temperature with ANOVA water bath, with a temperature range started at $20^{\circ} \mathrm{C}$ to $60^{\circ} \mathrm{C}$, and measuring the resistance with a multimeter. These values were compared with the temperature coefficient value of the resistivity of gold, $0.0034{ }^{\circ} \mathrm{C}^{-1}$ at $20^{\circ} \mathrm{C}$, as shown in Table S10. The average temperature coefficient observed by the OCP method for the screen-printed gold electrode was, however, $0.00247{ }^{\circ} \mathrm{C}^{-1}$ with a RSD of $4.94 \%$. Compared with the literature this $\alpha$ value is $27.4 \%$ lower. The Au-LE with the highest $\alpha$ value obtained was $0.00267{ }^{\circ} \mathrm{C}^{-1}$ which is still $21.6 \%$ below the literature value. Au-LE 1 and 5 had similar $\alpha$ values with very similar deviation from literature, $30.37 \%$ and $30.28 \%$ respectively. The two-point temperature calibration shown an average value of $0.00237^{\circ} \mathrm{C}^{-1}$, which is also $30.42 \%$ lower. The independent temperature calibration by controlling the solution temperature by ANOVA water bath also showed a low temperature coefficient with $0.00238^{\circ} \mathrm{C}^{-1}$ and $30 \%$ of deviation.

The observed behavior of individual Au-LEs indicates two things: The arbitrary quantity "power step" used by the Thermalab software is proportional to the heating current, and the thickness and width of the screen-printed Au-LE is very reproducible 
with occasional outliers. If a temperature accuracy of not better than $2 \mathrm{~K}$ was desired, then a few temperature calibrations of a few sensor chips would be representative for an entire lot of 100 sensors. On the other hand, the resistance, and thus, the active or heated length of the five Au-LE seems to vary by slightly higher degree (RSD 4\%). For highest accuracy ( $0.5 \mathrm{~K}$ and better), the temperature calibration has to be performed individually with each Au-LE sensor chip. While the various Au-LE geometries, and thus, the individual electrical resistance, can be compensated by measuring the resistance at a given standard temperature (such as $20^{\circ} \mathrm{C}$ ), the temperature coefficient of electrical resistivity was also slightly different according to our experiments (RSD 4.9\%, Table S2).
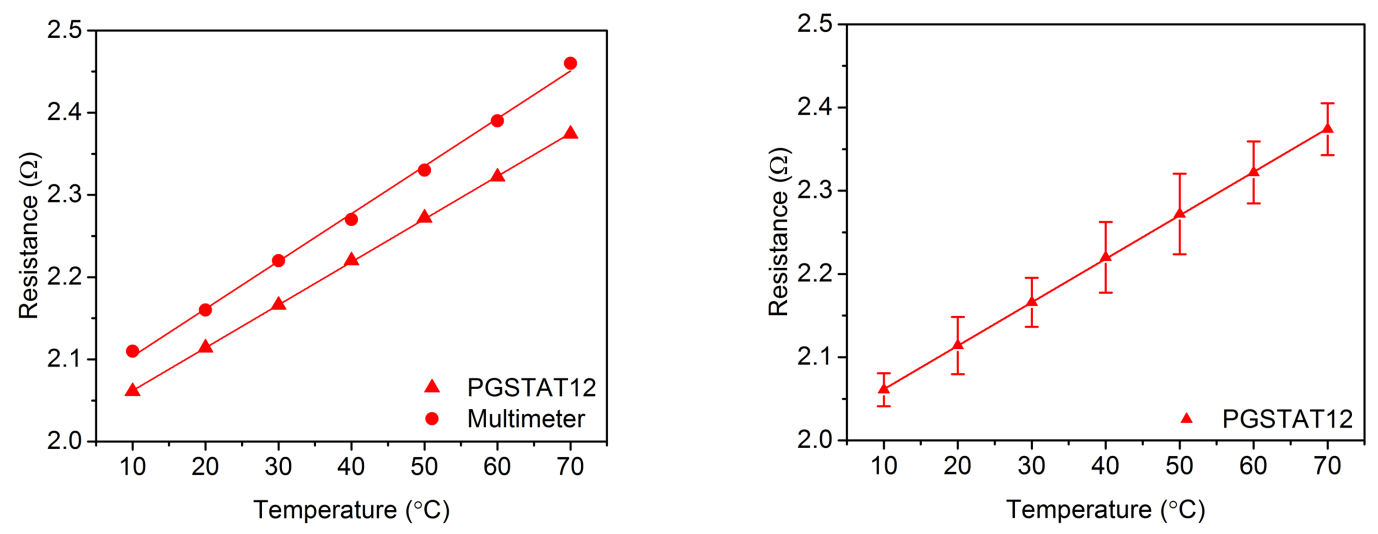

Figure 8. Left: Independent study of the temperature coefficient of electric resistivity using two independent methods. An Au-LE was immersed into a circulating bath (cryostat) filled with distilled water: Comparison of resistance values obtained at different temperatures using AutoLab PGSTAT12 and linear sweep from -20 to $20 \mathrm{mV}$ (triangles), and (alternatively) a TrueRMS multimeter (balls). Right: AutoLab PGSTAT12 resistance measurements with error bars indicating the standard deviation.

\subsection{Temperature coefficient of electrical resistivity of gold.}

The ca. $30 \%$ deviation of the temperature coefficient of resistivity from the literature value for gold appeared to be very unusual. Therefore, the resistance measurements were also performed using the circulating bath of a cryostat to establish the desired 
temperature, as measured by the internal electronic thermometer and digital display, and confirmed by a classical mercury thermometer (Fig. 8). A potentiostat was used to apply and accurately measure voltage and current. To do this with negligible heating effects, a linear sweep from -20 to $+20 \mathrm{mV}$ was applied. The resistance of the Au-LE at the given temperature was then obtained as the slope of this linear voltammogram (not shown). Separately from this, the resistance was also measured using a multimeter. The two additional clamp contacts resulted in an almost constant offset in resistance. The obtained temperature coefficient values for electrical resistance, however, were nearly identical.

Temperature coefficient of $0.002532{ }^{\circ} \mathrm{C}^{-1}$ was obtained from the linear plot of $R$ vs. $\Delta T\left(R^{2}=0.99991\right)$. There were few earlier reports on the effects of porosity upon temperature coefficients of the resistivity of sintered metals. Grootenhuis et al. investigated porous sintered bronze materials, and their data sets revealed a slight temperature dependency [31]. A table and graph based on their data set is being provided in the SI (Table. S11 and Fig. S5), and reveals a weak statistical correlation. Briefly, the temperature coefficient $\beta$ of electric resistivity increased by $23 \%$, when the density of sintered bronze specimen was diminished by $15 \%$, and electric resistivity $\rho$ decreased by $82 \%$. The latter correlation may be considered significant, and can be expected. Due to the very low thickness of our screen-printed gold layer, and the relatively large roughness of the underlying alumina substrate, we could not calculate absolute values of the electric resistivity of our gold layers. All we can say at this time is that a decrease of alpha with increasing porosity could have been found before; however, Grootenhuis et al. did not pay attention to this; their data set is in this regard not very conclusive [31]. One possible explanation could be that thermal expansion of the sintered gold particles increases their contact areas, which makes the gold layer more compact, and thus, compensates for a small part of the increase of the electric resistivity of the gold metal. However, Koh and Fortini found that the temperature coefficients of both thermal conductivity and electrical resistivity are essentially independent of porosity, and even the matrix structure of the porous material could be neglected [32]. 
Very thin layers of gold have also been examined in the past with regard to their resistivity and the respective temperature dependence. A study of Sambles et al. suggests that with gold films of thickness between 35 and $889 \mathrm{~nm}$, the temperature coefficient of resistivity increases between 20 and $300 \mathrm{~K}$. Moreover, the temperature coefficient was essentially zero below $10 \mathrm{~K}$ at any film thickness and grain size (Fig. 3 in [33]). The authors cited surface scattering effects and grain boundaries as probable reasons. Such effects had already been observed earlier [34]. This probably explains fairly well why our thin screen-printed gold layers $(<1 \mu \mathrm{m})$ can have a temperature coefficient of resistivity that is lower than the value for gold bulk materials.

\subsection{Trace detection of mercury(II)}

We have applied the disposable sensor for trace determination of mercury in various kinds of water samples. Similar to the more delicate gold micro-wire that we used earlier $[8,9]$, the electrode heating during the deposition step greatly enhances sensitivity. This was also connected to improved detection limit. We have then used the new sensor to detect trace mercury in natural water samples collected at Cherry Park Lake, NY.

\subsubsection{Temperature effect on stripping voltammetry of mercury(II)}

Figure 9 depicts the effect of electrode heating upon the stripping-voltammetric response of $50 \mathrm{ppb} \mathrm{Hg}(\mathrm{II})$ in distilled water. Elevated electrode temperature $\left(70^{\circ} \mathrm{C}\right)$ during the conditioning and deposition steps, increased the $\mathrm{Hg}$ stripping peaks 28fold. 


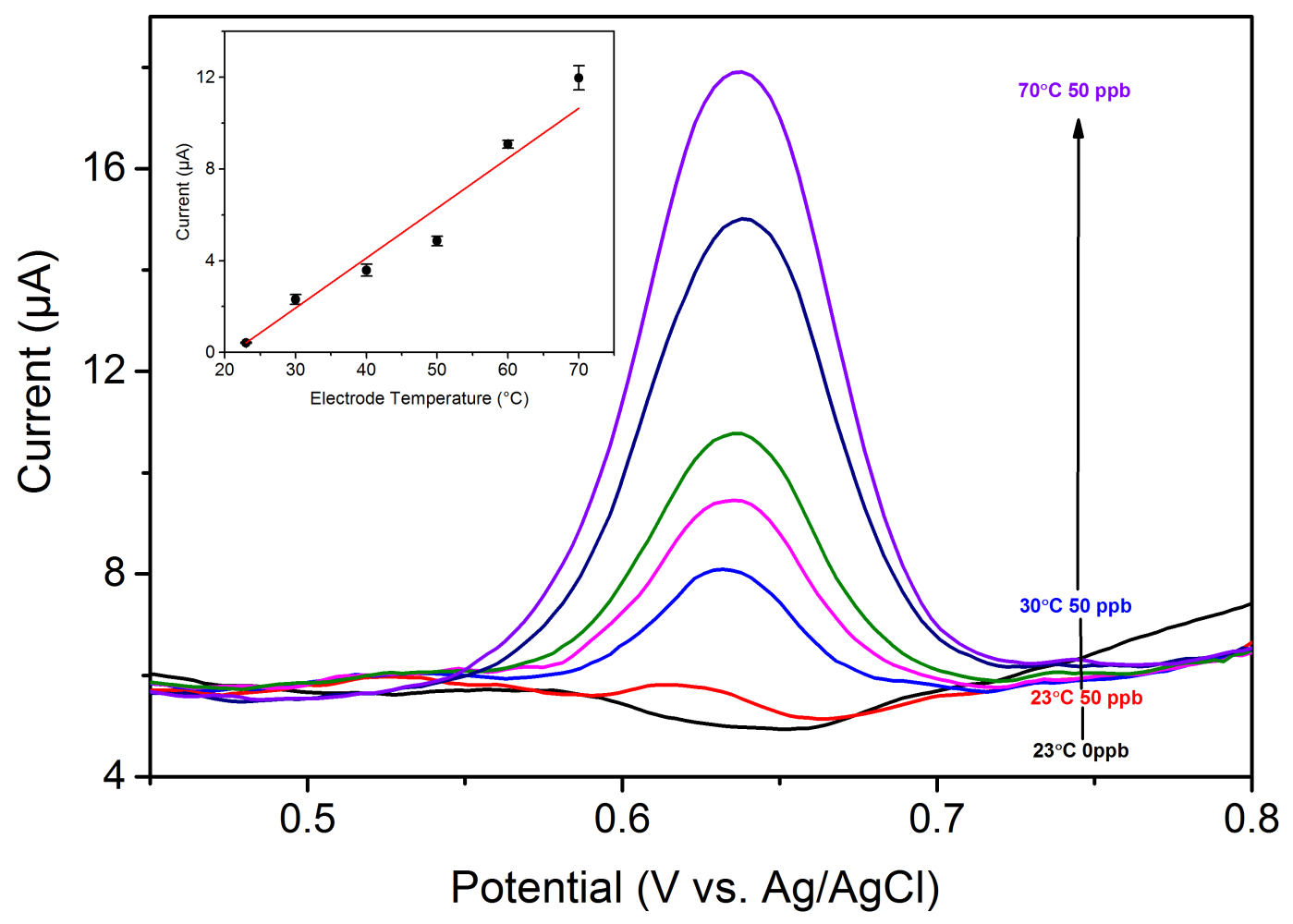

Fig. 9. Temperature study of $50 \mathrm{ppb} \mathrm{Hg}$ (II) in distilled water using square wave voltammetry (SWV) in Au-LE by increasing electrode temperature. Analysis was performed in a quiescent solution of 0.1 $\mathrm{M}$ sulfuric acid containing $0.01 \mathrm{M}$ hydrochloric acid.

Figure 10 illustrates the influence of analyte concentration ranging between 10 and $100 \mathrm{ppb}$, at two electrode temperatures, $23^{\circ} \mathrm{C}$, and $60^{\circ} \mathrm{C}$. The resulting calibration data and their prediction bands (95\%) revealed a limit-of-detection (LOD), of 20.1 ppb at $23^{\circ} \mathrm{C}$ and $9 \mathrm{ppb}$ at $60^{\circ} \mathrm{C}$. The sensitivity of the calibration plot increased by a factor of 10 . We also tested a lower concentration range, 1-10 ppb, exhibited in Fig. 11 at $23^{\circ} \mathrm{C}$ and at $70^{\circ} \mathrm{C}$ electrode temperature. The LOD was $6.4 \mathrm{ppb}$ at $23^{\circ} \mathrm{C}$ and $4.7 \mathrm{ppb}$ at $70{ }^{\circ} \mathrm{C}$. The sensitivity of the analysis increased by factor 5 . A study with UV-treated distilled water (Fig. 12) revealed an increase in sensitivity by a factor 6 at $60^{\circ} \mathrm{C}$ and by 9 at $70{ }^{\circ} \mathrm{C}$. LODs under these conditions were $34,7.4$, and 9.1 $\mathrm{ppb}$ at 23,60 , and $70{ }^{\circ} \mathrm{C}$ electrode temperature, respectively. Again, electrode 
heating was applied during conditioning and deposition steps only.
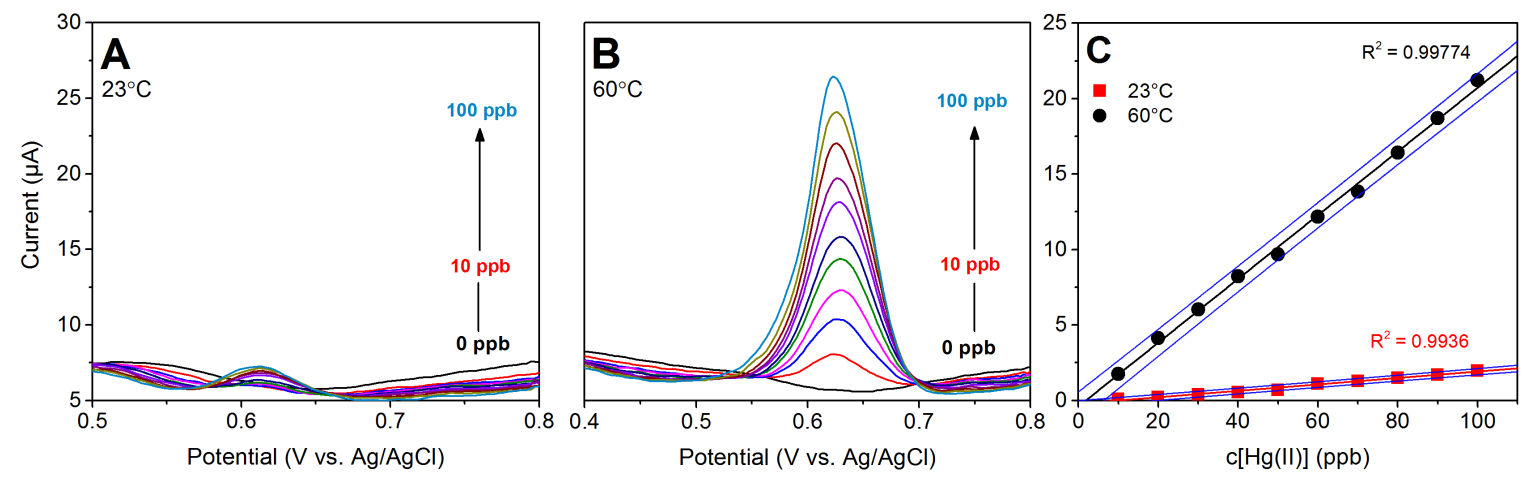

Fig. 10. Concentration study of $\mathrm{Hg}$ (II) using SWV in Au-LE. Standard addition of $\mathrm{Hg}$ (II) was done in an increment of $10 \mathrm{ppb}$. Blank value was obtained before the addition of $\mathrm{Hg}$ (II). Measurements were performed in a quiescent solution at room temperature, $23^{\circ} \mathrm{C}(\mathrm{A})$, without applying a heating current to the electrode and compared with the ones taken at $60^{\circ} \mathrm{C}(\mathrm{B})$, electrode temperature. A $0.1 \mathrm{M}$ sulfuric acid containing $0.01 \mathrm{M}$ hydrochloric acid was used as supporting electrolyte. (C) Calibration curve of standard addition of $\mathrm{Hg}(\mathrm{II})$ at $23^{\circ} \mathrm{C}(\boldsymbol{\Xi})$ and $60^{\circ} \mathrm{C}(\bullet)$ of three trials. Prediction bands are shown with blue lines with a $95 \%$ confident.

\subsubsection{Determination of mercury in real samples of lake water}

Samples of fresh water from rivers and lakes contain dissolved organic matter (DOM) that binds many heavy metal ions such as by formation of complexes with humic acids. In voltammetry, these compounds are usually removed using UV sample pretreatment. We tested whether the effects of elevated electrode temperature would also lead to improved sensitivity and accuracy of the standard addition method. This was investigated with water samples from Black River Pond spiked with 20 and $100 \mathrm{ppb} \mathrm{Hg}(\mathrm{II})$, respectively. The electrode heating during the conditioning and deposition steps resulted in a significant signal increase as demonstrated in Fig. 13. At the lower spiked concentration (20 ppb), the current peak signal increased approximately 30 times, when a higher temperature electrode (70 
$\left.{ }^{\circ} \mathrm{C}\right)$ was applied.
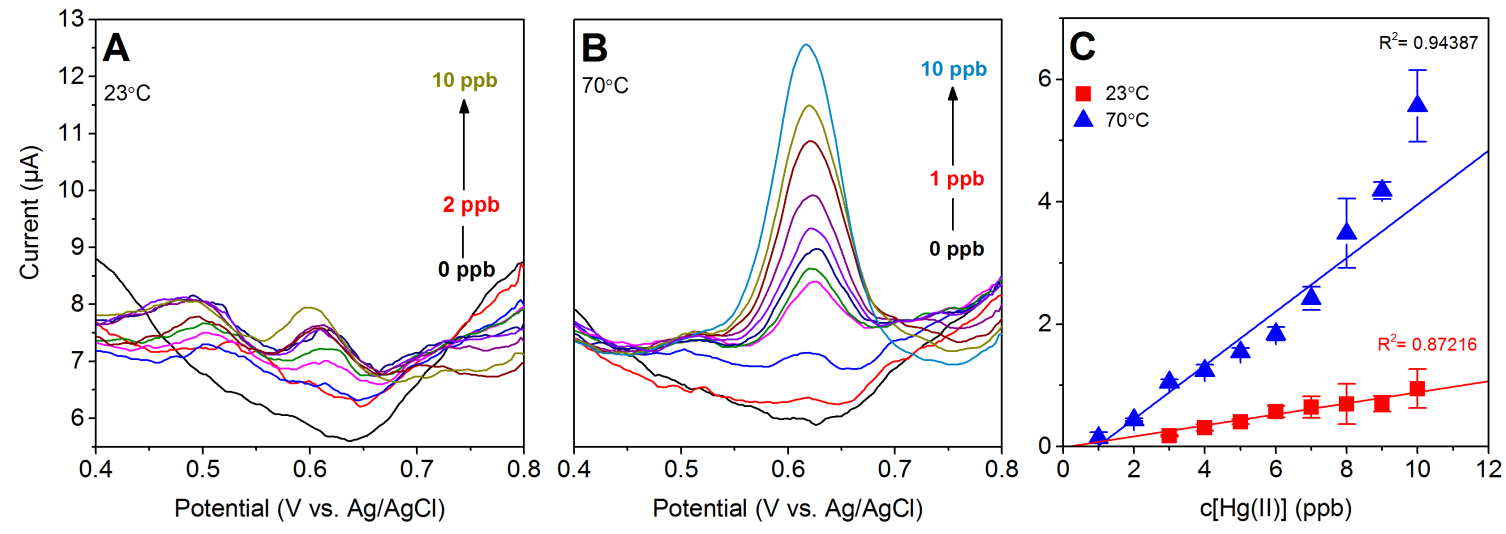

Fig. 11. Concentration study of $\mathrm{Hg}$ (II) in distilled water using SWV in Au-LE. Standard addition of $\mathrm{Hg}$ (II) was done in an increment of $1 \mathrm{ppb}$. Measurements were performed in a quiescent solution at room temperature, $23{ }^{\circ} \mathrm{C}(\mathrm{A})$, and at $70{ }^{\circ} \mathrm{C}(\mathrm{B})$ electrode temperature during deposition step. (C) Calibration curve of standard addition of $\mathrm{Hg}(\mathrm{II})$ at $23^{\circ} \mathrm{C}(\boldsymbol{\square})$ and $70{ }^{\circ} \mathrm{C}(\boldsymbol{\Delta})$ of three trials.

At the higher spiked concentrations (100 ppb), the stripping signal only increased ten times upon applying $70{ }^{\circ} \mathrm{C}$ electrode temperature during conditioning and deposition. The behavior of the sample spiked with $20 \mathrm{ppb}$ indicated that this amount is being bound by matrix components, notwithstanding the UV treatment, and that only at elevated temperature above $50{ }^{\circ} \mathrm{C}$, the mercury(II) would be released and available for reduction and deposition.

After that we investigated the effect of mercury(II) concentration upon stripping response after UV treatment of the Black River Pond water sample. Figure 14 reveals an increase in sensitivity of approximate factor 5.5 and 7 after applying 60 and $70{ }^{\circ} \mathrm{C}$, respectively. Interestingly, up to $30 \mathrm{ppb}$ mercury(II) were bound by the remaining sample matrix to be released only at elevated electrode temperature of 60 or $70{ }^{\circ} \mathrm{C}$ during conditioning and deposition. The precision of the strippingvoltammetric signal was also significantly improved by heating the electrode with RSD values no higher than 10 and $6 \%$ at 60 and $70{ }^{\circ} \mathrm{C}$, respectively. The mercury concentrations in the lake water samples were determined by five standard additions 
of $\mathrm{Hg}(\mathrm{II})$ with increments of $10 \mathrm{ppb}$. We obtained $6.50,0.49$, and $0.63 \mathrm{ppb} \mathrm{Hg}(\mathrm{II})$ at 23,60 , and $70{ }^{\circ} \mathrm{C}$ electrode temperature, respectively.
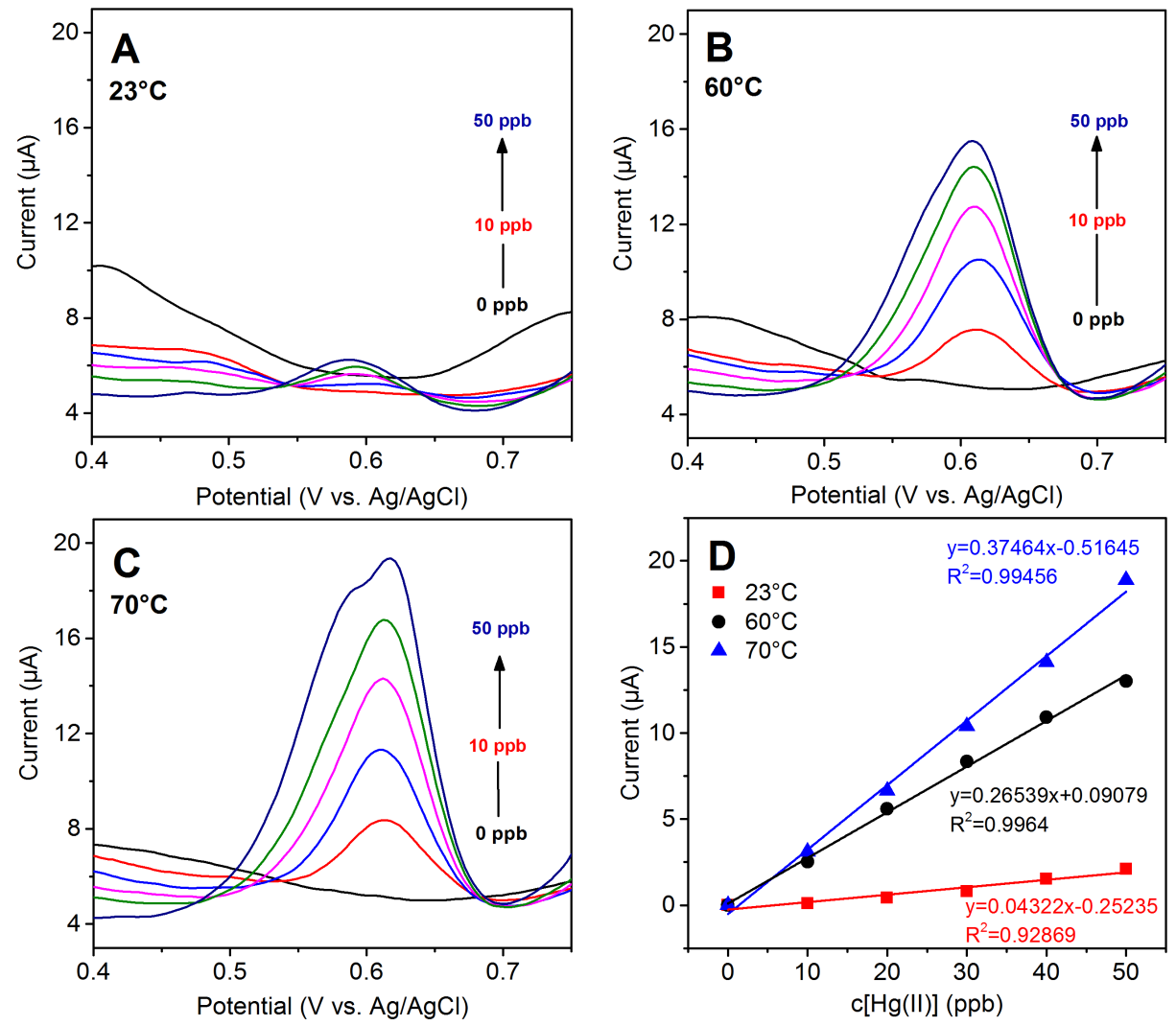

Fig. 12. Concentration study of $\mathrm{Hg}$ (II) in distilled water after UV digestion using SWV in Au-LE. Standard addition of $\mathrm{Hg}$ (II) was done in an increment of $10 \mathrm{ppb}$. Measurements were performed in a quiescent solution at room temperature, $23^{\circ} \mathrm{C}(\mathrm{A}), 60^{\circ} \mathrm{C}(\mathrm{B})$ and $70^{\circ} \mathrm{C}(\mathrm{C})$ electrode temperature during deposition step. (D) Calibration curve of standard additions of $\mathrm{Hg}$ (II) at $23^{\circ} \mathrm{C}(\square) 60^{\circ} \mathrm{C}(\mathbf{O})$ and $70^{\circ} \mathrm{C}(\mathbf{\Delta})$ of three trials.

The recovery rate of mercury(II) in the Black River Pond water sample after UV treatment was determined spiking 20, 30 and 40 ppb applying equation 7 . Calculated concentration was obtained from a calibration plot of $\mathrm{Hg}(\mathrm{II})$ after UV treatment and the signal obtained after the spiked the pond water sample. The concentration of $\mathrm{Hg}(\mathrm{II})$ in pond water at each temperature was considered for the calculation of the percentage of recovery after each addition. 

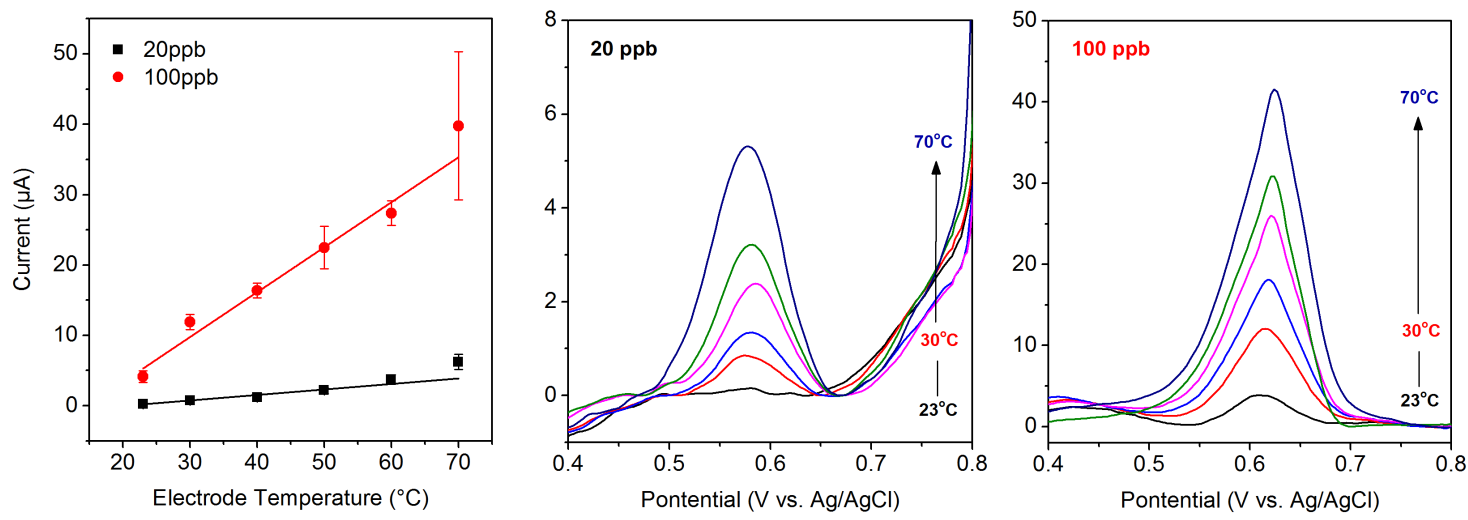

Fig. 13. Temperature study in Black River Pond water sample with UV treatment after addition of 20 and $100 \mathrm{ppb}$ of $\mathrm{Hg}$ (II) using SWV in Au-LE by increasing electrode temperature. The analysis was performed in a quiescent solution of $0.1 \mathrm{M}$ sulfuric acid containing $0.01 \mathrm{M}$ hydrochloric acid.

$\% R=\frac{[B]-[A]}{[S]} \times 100 \%$

eq. 7

Equation 7 shows how the percent of recovery was obtained for each spike and electrode temperature, where $B$ is the concentration measured in the spiked sample, or calculated concentration, using a calibration curve of $\mathrm{Hg}(\mathrm{II})$ standard after UV treatment, $[A]$ is the concentration in the original pond water sample obtained by standard addition at each electrode temperature after UV treatment and S amount added as a spike.

Table 2. Recovery rates for mercury(II) spiked in Black River Pond water after UV treatment

\begin{tabular}{|c|c|c|c|c|c|c|}
\hline \multirow[b]{2}{*}{ (Sample) + Spike added } & \multicolumn{3}{|c|}{ Determined Concentration (ppb) } & \multicolumn{3}{|c|}{$\%$ Recovery rate } \\
\hline & $23^{\circ} \mathrm{C}$ & $60^{\circ} \mathrm{C}$ & $70^{\circ} \mathrm{C}$ & $23^{\circ} \mathrm{C}$ & $60^{\circ} \mathrm{C}$ & $70^{\circ} \mathrm{C}$ \\
\hline Pond sample $+20 \mathrm{ppb}$ added & 13.71 & 17.51 & 18.29 & 36.05 & 85.07 & 88.32 \\
\hline Pond sample $+30 \mathrm{ppb}$ added & 16.90 & 28.97 & 27.50 & 34.69 & 94.92 & 89.55 \\
\hline Pond sample $+40 \mathrm{ppb}$ added & 34.75 & 40.26 & 37.13 & 70.64 & 99.43 & 91.24 \\
\hline
\end{tabular}



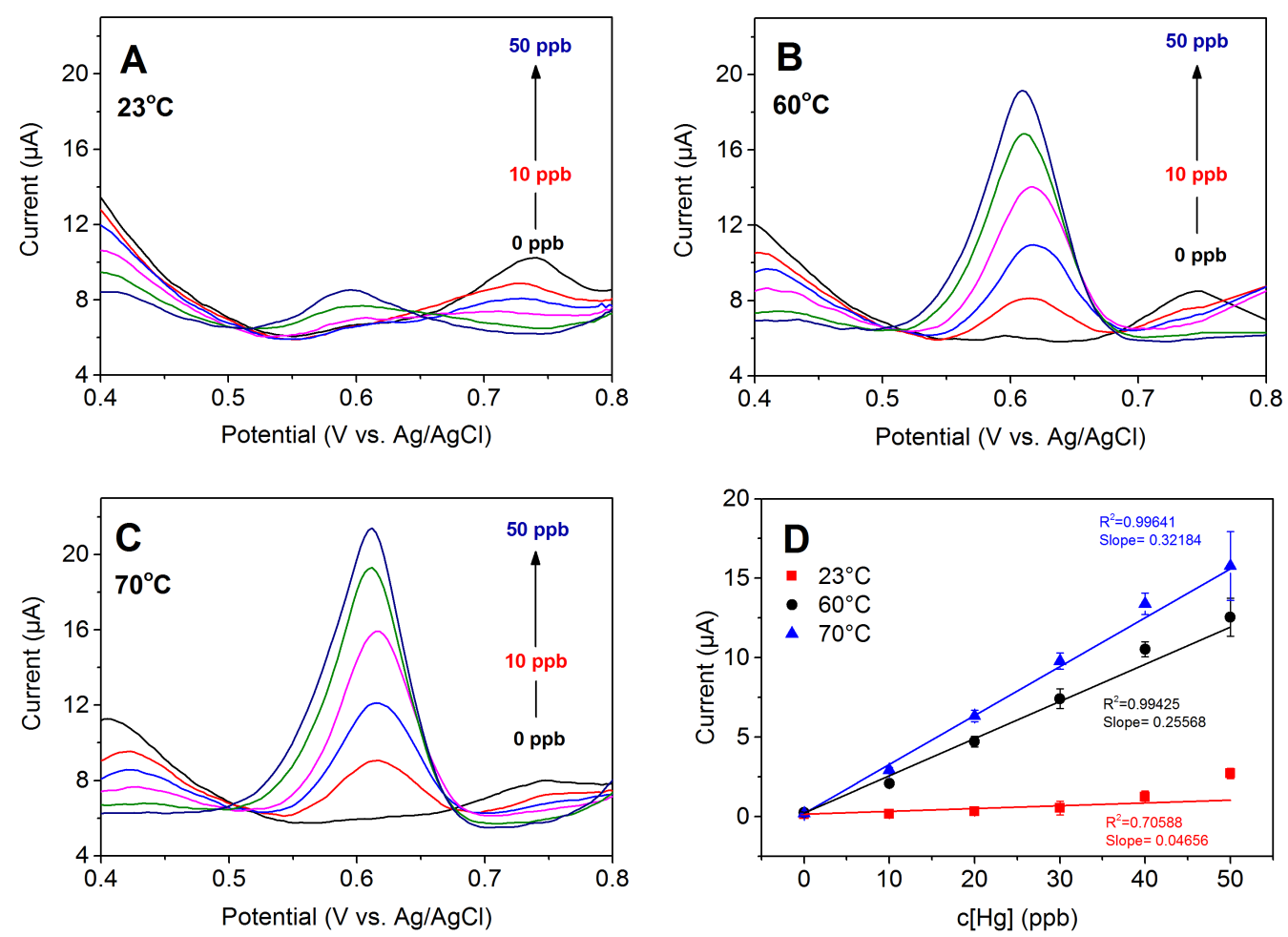

Fig. 14. Concentration study of $\mathrm{Hg}(\mathrm{II})$ in Black River Pond water sample with UV treatment using SWV in Au-LE. Standard addition of $\mathrm{Hg}$ (II) was done in an increment of $10 \mathrm{ppb}$. Measurements were performed in a quiescent solution at room temperature, $23^{\circ} \mathrm{C}(\mathrm{A}), 60^{\circ} \mathrm{C}(\mathrm{B})$ and $70^{\circ} \mathrm{C}(\mathrm{C})$ electrode temperature during deposition step. (D) Calibration curve of standard additions of $\mathrm{Hg}(\mathrm{II})$ at $23^{\circ} \mathrm{C}(\square)$ $60^{\circ} \mathrm{C}(\boldsymbol{O})$ and $70^{\circ} \mathrm{C}(\boldsymbol{\Delta})$ of three trials.

Finally, a test with the filtered original lake water sample indicated that mercury traces can also be detected without any further preparation in presence of the full sample matrix. Figure 15 demonstrates that at $70{ }^{\circ} \mathrm{C}$, signals of mercury became clearly visible from $10 \mathrm{ppb}$; however, for accurate quantitation, even higher electrode temperatures will be needed that require a much smoother gold electrode surface in order to prevent the formation of air bubbles, which limit the reproducibility. 

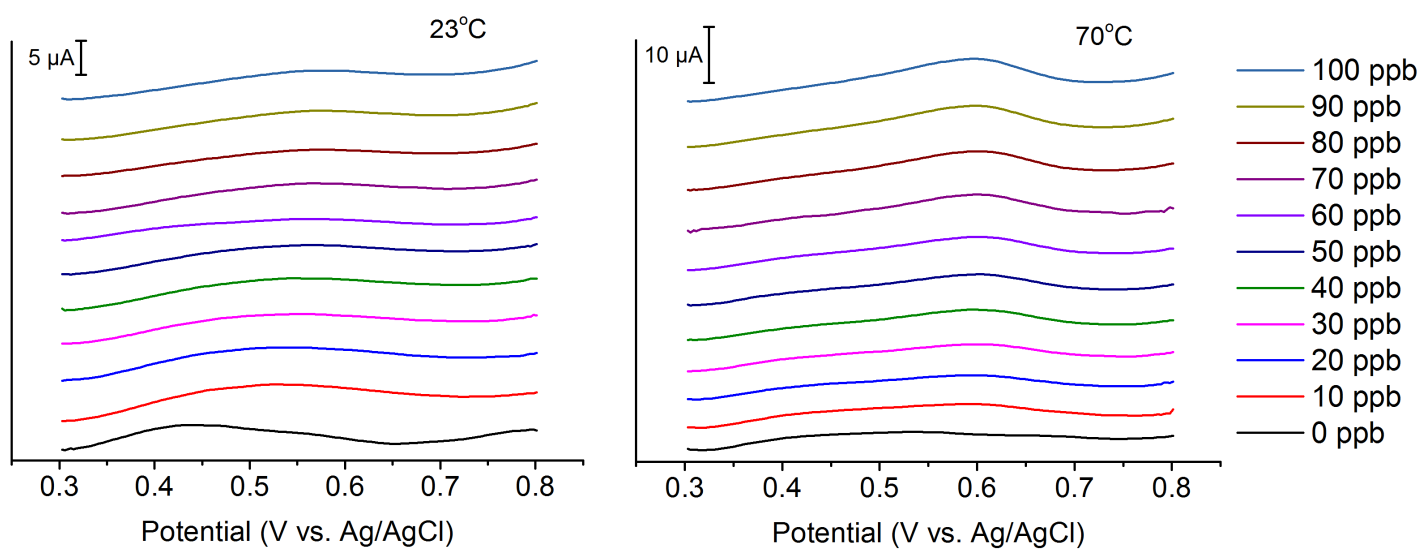

Fig. 15. Concentration study of $\mathrm{Hg}(\mathrm{II})$ in Black River Pond water sample without UV treatment using SWV in Au-LE. Standard addition of $\mathrm{Hg}$ (II) was done in increments of $10 \mathrm{ppb}$. Measurements were performed in a quiescent solution at room temperature, $23^{\circ} \mathrm{C}$ (left) and $70^{\circ} \mathrm{C}$ (right) electrode temperature during deposition step.

\section{Conclusions}

In this study, we aimed at a quick and accurate temperature calibration method for disposable heated gold electrodes based on screen-printed sensor chips. Comparison of five different Au-LE chips revealed deviations (RSD ca. $4 \%$ ) in electric resistance of the screen-printed gold-loops that would require an individual calibration of each single sensor chip. Then we investigated whether a simple correction factor would allow for compensation of the different resistance values. It turned out, however, that even the temperature coefficient of electric resistivity of the gold layers was changing significantly (RSD ca. $4 \%$ ). The temperature coefficient was determined to be $0.00247^{\circ} \mathrm{C}^{-1}$, which is $27 \%$ lower than the established value for gold around $20^{\circ} \mathrm{C}$.

We therefore developed an automatic calibration protocol, enabled by a software tool and automatic AC heating generator that is based on temperature pulse potentiometry and a well-investigated redox couple. The known temperature 
coefficient of the standard redox potential of ferro/ferricyanide $(-1.6 \mathrm{mV} / \mathrm{K})$ was used to calculated the electrode temperature. The calculated temperature values were very precise with RSD no higher than $0.4 \%$ for a given electrode and $0.2 \%$ between the five electrodes. On the other hand, the margin error with a $95 \%$ confidence level were no higher than $\pm 1 \mathrm{~K}$ within the same Au-LE and $\pm 0.7 \mathrm{~K}$ between the five chips. An alternative two-point calibration is based on the measurement of the electric resistance of the Au-LE at two fixed temperatures that are easy to maintain: $0{ }^{\circ} \mathrm{C}$ in an ice bath and $100^{\circ} \mathrm{C}$ in boiling water in order to determine the two parameters $R_{0}$ and $\alpha$. This resistance temperature calibration approach method allows usage of the disposable Au-LE sensors even in organic solvents were OCP measurements are difficult. Both, the new automatic potentiometric and the two-point temperature calibration methods take no longer than $10 \mathrm{~min}$., and allows for highly accurate temperature adjustment $( \pm 0.7 \mathrm{~K})$.

Investigations of the screen-printed gold layer by SEM and AFM revealed porosity and low thickness which, however, may not explain why the temperature coefficient of electric resistivity was apparently altered in different electrode layers, and was much different from the literature value of gold. Rather, this phenomenon can probably be explained by surface scattering effects that have been described already for nm scale metal films. [33, 34]

Mercury analysis was significantly improved with SWV stripping signals that increased five to ten times upon heating the Au-LE during the deposition step compared to measurements at room temperature $\left(23^{\circ} \mathrm{C}\right)$. Lower LOD values were also obtained when up to $70^{\circ} \mathrm{C}$ electrode temperature was applied. This observation indicates that the micro-stirring effect created by the temperature gradient at the surface of the electrode enhances the electrochemical signal. At this point the UV sample preparation of lake water cannot completely be avoided; however, we believe that interferences with dissolved organic matter can be overcome by even higher electrode temperature replacing the classical UV sample preparation altogether. 


\section{Acknowledgement}

The authors are grateful for financial support of their work: SUNY Albany start-up support, Deutsche Forschungsgemeinschaft (Heisenberg Fellowship DFG FL 384/72), German Academic Exchange Service (DAAD), BMBF Wachstumskerne mit Potential (Nordic Diagnostic Alliance). 


\section{References}

[1] P. Gründler, G.-U. Flechsig, Principles and analytical applications of heated electrodes, Microchim. Acta 154 (2006) 175-189.

[2] P. Gründler, A. Kirbs, L. Dunsch, Modern Thermoelectrochemistry, ChemPhysChem 10 (2009) 1722-1746.

[3] G.-U. Flechsig, A. Walter, Electrically Heated Electrodes: Practical Aspects and New Developments, Electroanalysis 24 (2012) 23-31.

[4] A. Boika, A.S. Baranski, Dielectrophoretic and Electrothermal Effects at Alternating Current Heated Disk Microelectrodes, Anal. Chem. 80 (2008) 7392-7400.

[5] A.S. Baranski, A. Boika, Ultrahigh Frequency Voltammetry: Effect of Electrode Material and Frequency of Alternating Potential Modulation on Mass Transport at Hot-Disk Microelectrodes, , Anal. Chem. 84 (2012) 1353-1359.

[6] P. Gründler, G.-U. Flechsig, Deposition and stripping at heatedmicroelectrodes. Arsenic(V) at a gold electrode. Electrochim. Acta 43 (1998) 3451-3458.

[7] Tadesse Zerihun, P. Gründler, Electrically heated cylindrical microelectrodes. Determination of lead on Pt by cyclic voltammetry and cathodic stripping analysis, J. Electroanal. Chem. 415 (1996) 85-88.

[8] J. Wang, P. Gründler, G.-U. Flechsig, M. Jasinski, J. Lu, J. Wang, Z. Zhao, B. Tian, Hotwire stripping potentiometric measurements of trace mercury, Anal. Chim. Acta 396 (1999) 33-36.

[9] G.-U. Flechsig, O. Korbut, P. Gründler, Investigation of Deposition and Stripping Phenomena at the Heated Gold Wire Electrode in Comparison to the Rotating Disk Electrode: Copper(II), Mercury(II) and Arsenic(III), Electroanalysis 13 (2001) 786788.

[10] M. Jasinski, A. Kirbs, M. Schmehl, P. Gründler, Heated mercury film electrode for anodic stripping voltammetry, Electrochem. Commun. 1 (1999) 26-28.

[11] M. Jasinski, P. Gründler, G.-U. Flechsig, J. Wang, Anodic Stripping Voltammetry with a Heated Mercury Film on a Screen-printed Carbon Electrode, Electroanalysis 13 (2001) 34-36. 
[12] F. Wachholz, J. Gimsa, H. Duwensee, H. Grabow, P. Gründler, G.-U. Flechsig, A compact and versatile instrument for radio frequency heating in nonisothermal electrochemical studies, Electroanalysis 19 (2007) 535-540.

[13] J.-J. Sun, L. Guo, D.-F. Zhang, W.-H. Yin, G.-N. Chen, Heated graphite cylinder electrodes, Electrochem. Commun. 9 (2007) 283-288.

[14] S.-H. Wu, J-J. Sun, Z.-B. Lin, A.-H. Wu, Y.-M. Zeng, L. Guo, D.-F. Zhang, H.-M. Dai, G.N. Chen, Adsorptive Stripping Analysis of Riboflavin at Electrically Heated Graphite Cylindrical Electrodes, Electroanalysis 19 (2007) 2251-2257.

[15] S.-H. Wu, B.-J. Zhu, Z.-X. Huang, J.-J. Sun, A heated pencil lead disk electrode with direct current and its preliminary application for highly sensitive detection of luteolin, Electrochem. Commun. 28 (2013) 47-50.

[16] J. Wang, P. Gründler, G.-U. Flechsig, M. Jasinski, G. Rivas, E. Sahlin, J.-L. Lopez-Paz, Stripping Analysis of Nucleic Acids at a Heated Carbon Paste Electrode, Anal. Chem. 72 (2000) 3752-3756.

[17] J. Wang, G.-U. Flechsig, A. Erdem, O. Korbut, P. Gründler, Label-free DNA Hybridization Based on Coupling of a Heated Carbon Paste Electrode with Magnetic Separations, Electroanalysis 16 (2004) 928-931.

[18] H. Yang, C.A. Choi, K.H. Chung, C.-H. Jun, Y.T. Kim, An Independent, temperatureControllable Microelectrode Array, Anal. Chem. 76 (2004) 1537-1543.

[19] Z.-X. Huang, S. Yang, F.-Z. Yao, K.-X. Xu, J.-F. Zhang, S.-H. Wu, J.-J. Sun, Alternate hot and cold electrodes, Electrochem. Commun. 61 (2015) 129-133.

[20] A. Sode, M. Nebel, P. Pinyou, S. Schmaderer, J. Szeponik, N. Plumere, W. Schuhmann, Determination of Temperature Gradients with Micrometric Resolution by Local Open Circuit Potential Measurements at a Scanning Microelectrode, Electroanalysis 25 (2013) 2084-2091.

[21] C. Gabrielli, M. Keddam, J.-F. Lizee, A temperature pertubation method for electrochemical kinetics investigations, J. Electroanal. Chem. 148 (1983) 293-297.

[22] P. Gründler, L. Dunsch, A facile route to temperature determination in hot-wire electrochemistry, J. Solid State Electrochem. 15 (2011) 2101-2106. 
[23] A. Hafez, G.-U. Flechsig, ToF-secondary ion mass-spectrometric study of copper deposition and stripping on directly heated screen-printed gold electrodes, J. Solid State Electrochem. 17 (2013) 1563-1570.

[24] P. Gründler, In-situ Thermoelectrochemistry, Springer, Heidelberg - New York 2015, p. 97.

[25] J.-F. Huang, I.W. Sun, Fabrication and Surface Functionalization of Nanoporous Gold by Electrochemical Alloying/Dealloying of Au-Zn in an Ionic Liquid, and the SelfAssembly of L-Cysteine Monolayers, Adv. Funct. Mater. 15 (2005) 989-994.

[26] P. Gründler, A. Kirbs, T. Zerihun, Hot-wire Electrodes: Voltammetry Above the Boiling Point, Analyst 121 (1996) 1805-1810.

[27] T. Voß, P. Gründler, A. Kirbs, G.-U. Flechsig, Temperature-pulse-voltammetry: hot layer electrodes made by LTCC technology, Electrochem. Commun. 1 (1999) 383-388.

[28] T. Voß, A. Kirbs, P. Gründler, Basics of temperature pulse voltammetry, Fres. J. Anal. Chem. 367 (2000) 230-323.

[29] T. Zerihun, P. Gründler, Electrically heated cylindrical microelectrodes. The reduction of dissolved oxygen on Pt, J. Electroanal. Chem. 404 (1996) 243-248.

[30] Raymond A. Serway (1998). Principles of Physics (2nd ed.). Fort Worth, Texas; London: Saunders College Pub. p. 602. ISBN 0-03-020457-7.

[31] P. Grootenhuis, R.W. Powell, R.P. Tye, Thermal and Electrical Conductivity of Porous Metals made by Powder Metallurgy Methods, Proc. Phys. Soc. B65 (1952) 502511.

[32] J.C.Y. Koh, A. Fortini, Prediction of thermal conductivity and electrical resistivity of porous metallic materials, Int. J. Heat Mass. Transfer 16 (1973) 2013-2022.

[33] J.R. Sambles, K.C. Elsom, D.J. Jarvis, The Electrical Resistivity of Gold Films, Phil. Trans. R. Soc. Lond. A 304 (1982) 365-396.

[34] K.L. Chopra, L.C. Bobb, Electrical Resistivity Studies on Polycrystalline and Epitaxially Grown Gold Films, Acta Metall. 12 (1964) 807-811. 


\section{Rapid and Accurate Automatic Temperature Calibration of Disposable Screen-printed Heated Gold Electrodes}

Sonivette Colón-Rodríguez ${ }^{a}$, Martin Schönhoff ${ }^{b}$, Juhaina Abdulkhalek ${ }^{c}$, Tatiana Quiñones-Ruíz a, Stephen W. Bentham ${ }^{d}$, Gourav Bhowmike, Mengbing Huang ${ }^{\mathrm{e}}$, Peter Langer ${ }^{c}$, Igor K. Lednev a , Gerd-Uwe Flechsig a,b,d,f*,

a) University at Albany, SUNY, Dept. of Chemistry, 1400 Washington Ave, Albany, NY 12222, United States

b) Gensoric GmbH, G.-Hauptmann-Str. 23, 18055 Rostock, Germany

c) University of Rostock, Dept. of Chemistry, A.-Einstein-Str. 3a, 18059 Rostock, Germany

d) Manchester Metropolitan University, School of Science and the Environment, M1 5GD, Manchester, United Kingdom

e) Colleges of Nanoscale Science and Engineering, SUNY Polytechnic Institute, Albany, NY, 12203, United States

f) Coburg University of Applied Sciences and Arts, Faculty of Applied Natural Sciences, Friedrich-Streib-Str. 2, 96450 Coburg, Germany

${ }^{*}$ Corresponding author: gerd-uwe.flechsig@hs-coburg.de

Supplementary Information 


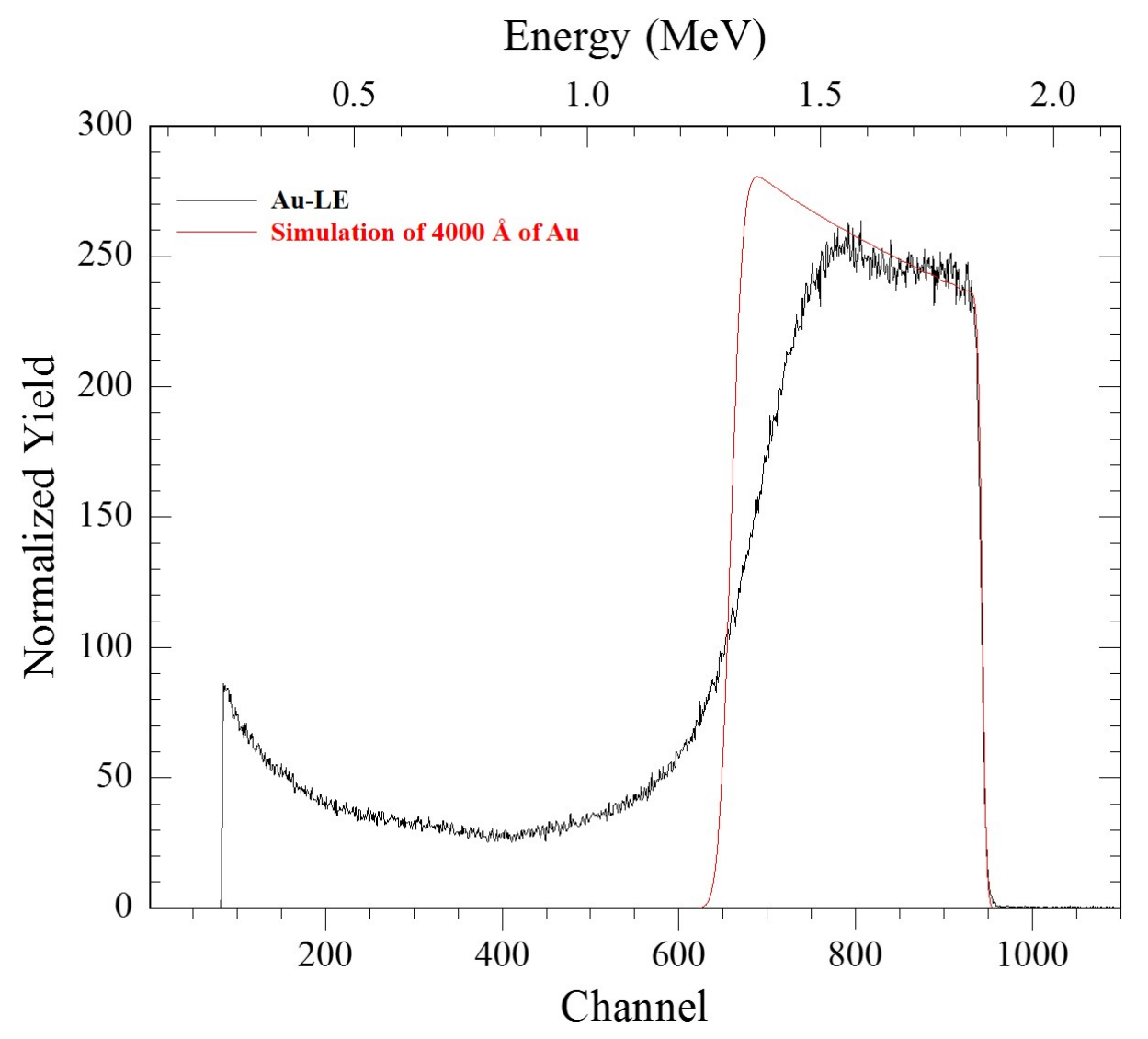

Fig. S1. Rutherford backscattering spectrometry (RBS) of Au-LE. Helium (2+) beam was placed on top of the gold electrode. The spectrum shows both layers in the Au-LE, the ceramic substrate and a gold layer on top. XRUMP simulation of a gold layer with a thickness of $4000 \AA$ indicates that the thickness of $A u$ is approximately $400 \mathrm{~nm}$ for this measurement. However, the thickness cannot be accurate determine since each layers are not well defined. Measurement of three different sensors shown an average thickness of $600 \mathrm{~nm}$. 


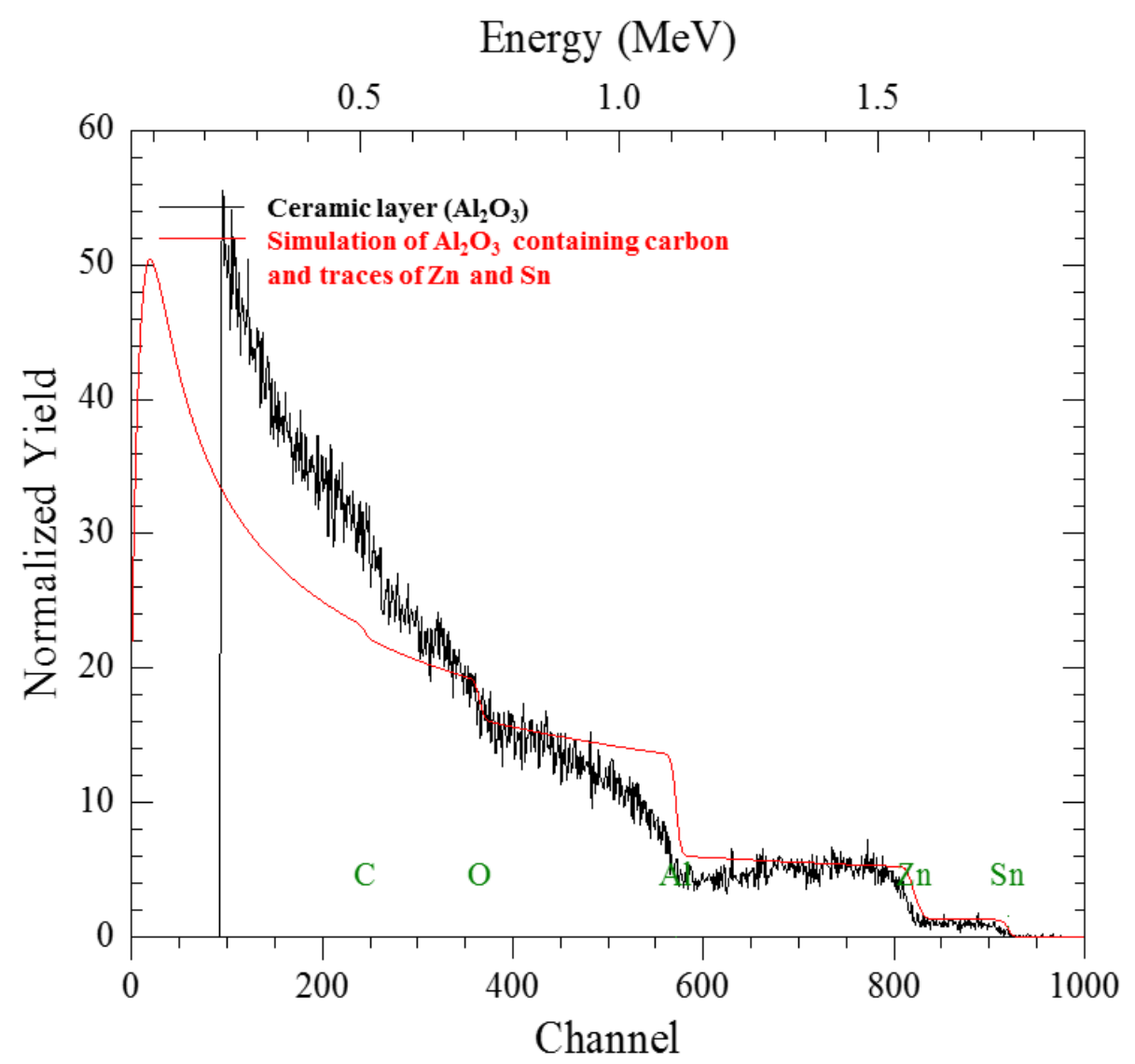

Fig. S2. Rutherford Back-scattering Spectroscopy (RBS) spectrum of $\mathrm{Al}_{2} \mathrm{O}_{3}$ substrate. XRUMP simulation shown the presence of carbon, oxygen and aluminum with traces of zinc and tin. 


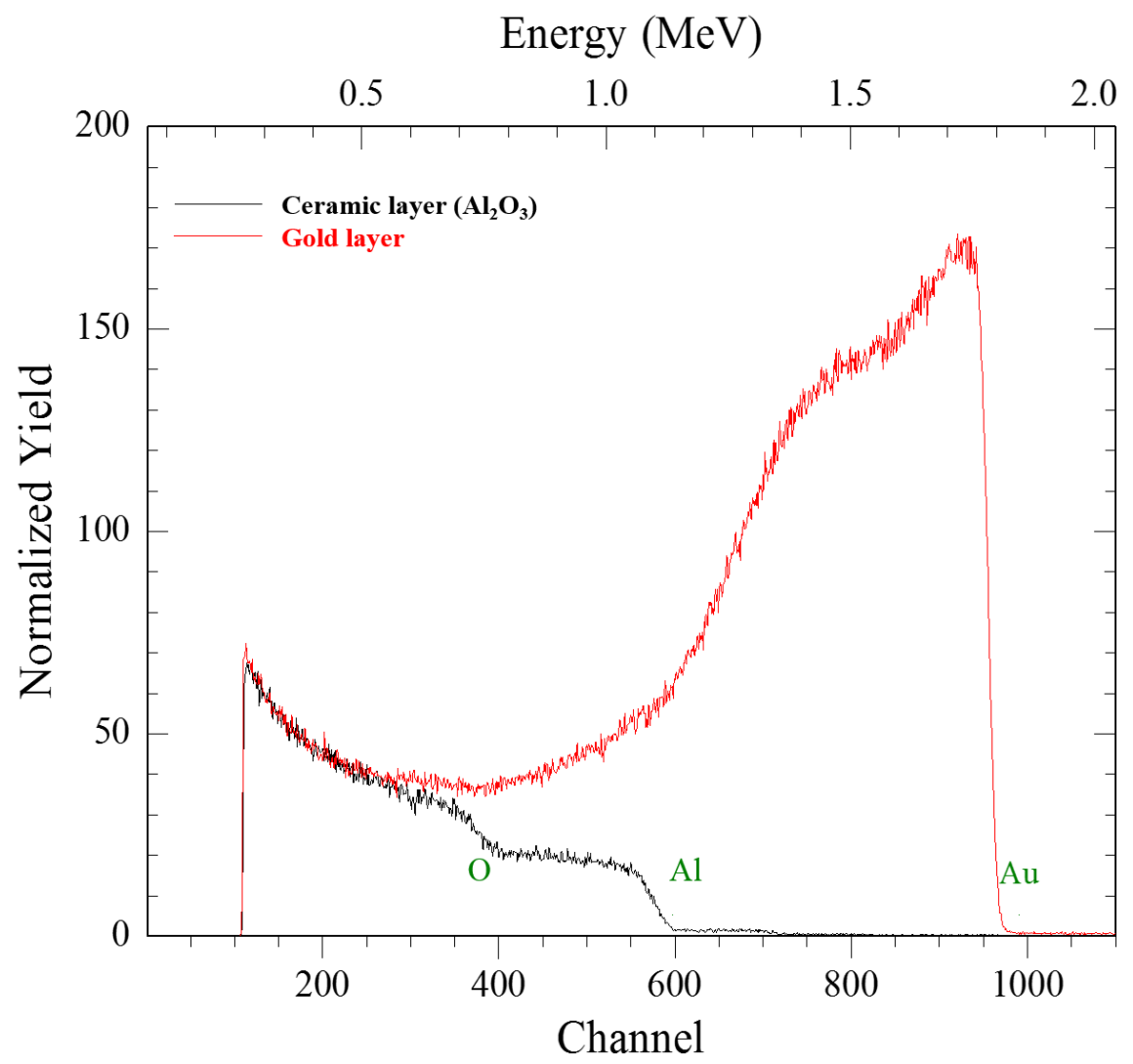

Fig. S3. Rutherford Back-scattering Spectroscopy (RBS) spectrum of $\mathrm{Al}_{2} \mathrm{O}_{3}$ substrate and gold layers in Au-LE individually. XRUMP showed a composition of oxygen and aluminum (ceramic substrate) and gold on the surface of the substrate.

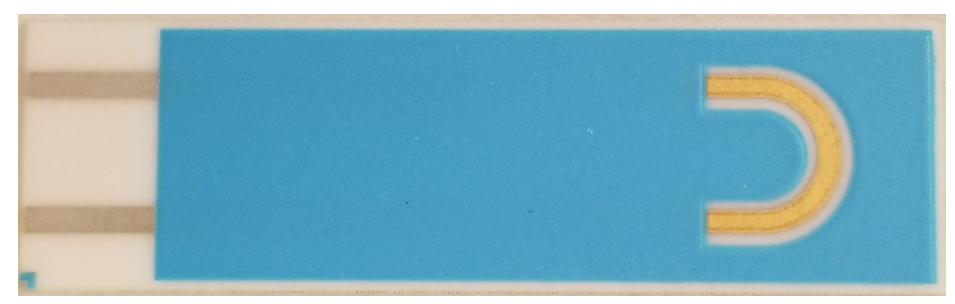

Fig. S4. Gold loop screen-printed electrode (DropSens $\left.{ }^{\odot}\right)$. 
Table S1. Data obtained from the temperature calibration of five electrodes by OpenCircuit Potentiometry. Individual temperature calibrations were performed with five AuLE, each with five repetitions.

\begin{tabular}{|c|c|c|c|c|c|c|}
\hline \multirow{2}{*}{ Power Step } & \multicolumn{6}{|c|}{$\Delta E(m V)$} \\
\hline & Au-LE 1 & Au-LE 2 & Au-LE 3 & Au-LE 4 & Au-LE 5 & Average \\
\hline 100 & -2.824 & -2.784 & -2.924 & -2.924 & -2.210 & -2.733 \\
\hline 200 & -9.958 & -9.968 & -9.866 & -9.866 & -9.106 & -9.753 \\
\hline 300 & -19.807 & -20.279 & -19.602 & -19.602 & -18.539 & -19.566 \\
\hline 400 & -31.746 & -33.443 & -31.148 & -31.148 & -29.412 & -31.380 \\
\hline 500 & -45.504 & -48.224 & -45.657 & -45.657 & -41.960 & -45.400 \\
\hline \multirow{2}{*}{ Power Step } & \multicolumn{6}{|c|}{ Electrode Temperature (K) } \\
\hline & Au-LE 1 & Au-LE 2 & Au-LE 3 & Au-LE 4 & Au-LE 5 & Average \\
\hline 100 & 298.77 & 298.74 & 298.83 & 298.59 & 38 & 294.81 \\
\hline 200 & 303.22 & 303.23 & 303.17 & 302.54 & 302.69 & 299.12 \\
\hline 300 & 309.38 & 309.67 & 309.25 & 308.76 & 308.59 & 305.28 \\
\hline 400 & 316.84 & 317.90 & 316.47 & 316.18 & 38 & 312.70 \\
\hline 500 & 5.44 & 327.14 & 325.54 & 324.39 & 323.22 & 321.30 \\
\hline \multirow{2}{*}{ Power Step } & \multicolumn{6}{|c|}{ Electrode Resistance $(\Omega)$} \\
\hline & Au-LE 1 & Au-LE 2 & Au-LE 3 & Au-SPE 4 & Au-LE 5 & Average \\
\hline 100 & 2.23 & 2.05 & 2.02 & 2.06 & 2.05 & 2.08 \\
\hline 200 & 2.25 & 2.08 & 2.05 & 2.08 & 2.08 & 2.11 \\
\hline 300 & 2.29 & 2.11 & 2.08 & 2.10 & 2.10 & 2.13 \\
\hline 400 & 2.32 & 2.16 & 2.11 & 2.14 & 2.13 & 2.17 \\
\hline 500 & 2.37 & 2.21 & 2.16 & 2.18 & 2.17 & 2.22 \\
\hline \multirow{2}{*}{ Power Step } & \multicolumn{6}{|c|}{ Heating Current (A) } \\
\hline & Au-LE 1 & Au-LE 2 & Au-LE 3 & Au-LE 4 & Au-LE 5 & Average \\
\hline 100 & 0.270 & 0.285 & 0.293 & 0.283 & 0.275 & 0.281 \\
\hline 200 & 0.524 & 0.546 & 0.562 & 0.548 & 0.539 & 0.544 \\
\hline 300 & 0.772 & 0.805 & 0.825 & 0.815 & 0.800 & 0.803 \\
\hline 400 & 1.012 & 1.056 & 1.074 & 1.064 & 1.046 & 1.050 \\
\hline 500 & 1.244 & 1.296 & 1.328 & 1.316 & 1.286 & 1.294 \\
\hline \multirow{2}{*}{ Power Step } & \multicolumn{6}{|c|}{ Electrical Resistivity $\rho(\Omega \mathrm{m})$} \\
\hline & Au-LE 1 & Au-LE 2 & Au-LE 3 & Au-LE 4 & Au-LE 5 & Average \\
\hline 100 & $2.451 \mathrm{E}-08$ & $2.451 \mathrm{E}-08$ & $2.451 \mathrm{E}-08$ & $2.449 \mathrm{E}-08$ & $2.448 \mathrm{E}-08$ & $2.45 \mathrm{E}-08$ \\
\hline 200 & $2.480 \mathrm{E}-08$ & $2.480 \mathrm{E}-08$ & $2.477 \mathrm{E}-08$ & $2.473 \mathrm{E}-08$ & $2.474 \mathrm{E}-08$ & $2.48 \mathrm{E}-08$ \\
\hline 300 & $2.521 \mathrm{E}-08$ & $2.521 \mathrm{E}-08$ & $2.514 \mathrm{E}-08$ & $2.509 \mathrm{E}-08$ & $2.509 \mathrm{E}-08$ & $2.51 \mathrm{E}-08$ \\
\hline 400 & $2.574 \mathrm{E}-08$ & $2.574 \mathrm{E}-08$ & $2.557 \mathrm{E}-08$ & $2.553 \mathrm{E}-08$ & $2.549 \mathrm{E}-08$ & $2.56 \mathrm{E}-08$ \\
\hline 500 & $2.634 \mathrm{E}-08$ & $2.634 \mathrm{E}-08$ & $2.611 \mathrm{E}-08$ & $2.602 \mathrm{E}-08$ & $2.595 \mathrm{E}-08$ & $2.62 \mathrm{E}-08$ \\
\hline
\end{tabular}


Table S2. Standard deviation and relative standard deviation between five electrodes. Individual temperature calibrations were performed with five Au-LE, each with five repetitions

\begin{tabular}{|c|ccccc|ccccc|}
\hline Power & \multicolumn{5}{|c|}{ Std. Dev. } & \multicolumn{4}{c|}{$\mathbf{R S D}(\%)$} \\
Step & $\mathbf{T}(\mathbf{K})$ & $\mathbf{\Delta} \mathbf{E}(\mathbf{m V})$ & $\mathbf{R}(\mathbf{\Omega})$ & $\mathbf{I}(\mathbf{A})$ & $\mathbf{\rho}(\mathbf{\Omega m})$ & $\mathbf{T}(\mathbf{K})$ & $\mathbf{\Delta E}(\mathbf{m V})$ & $\mathbf{R}(\mathbf{\Omega})$ & $\mathbf{I}(\mathbf{A})$ & $\boldsymbol{\rho}(\mathbf{\Omega m})$ \\
\hline 100 & 0.18 & 0.30 & 0.083 & 0.009 & $1.35 \mathrm{E}-11$ & 0.06 & 10.93 & 4.01 & 3.19 & 0.06 \\
200 & 0.33 & 0.36 & 0.084 & 0.014 & $3.45 \mathrm{E}-11$ & 0.11 & 3.74 & 3.97 & 2.58 & 0.14 \\
300 & 0.45 & 0.64 & 0.087 & 0.020 & $6.26 \mathrm{E}-11$ & 0.15 & 3.26 & 4.08 & 2.51 & 0.25 \\
400 & 0.93 & 1.45 & 0.085 & 0.024 & $1.20 \mathrm{E}-10$ & 0.30 & 4.61 & 3.93 & 2.27 & 0.47 \\
500 & 1.46 & 2.23 & 0.088 & 0.032 & $1.78 \mathrm{E}-10$ & 0.45 & 4.92 & 3.98 & 2.51 & 0.68 \\
\hline
\end{tabular}

Table S3. Temperature coefficient ( $\alpha$ ) from the resistance and temperature calibration plot from OCP method. Theoretical value of temperature coefficient for gold metal used was $0.0034 \mathrm{C}^{-1}$.

\begin{tabular}{|c|c|c|c|c|}
\hline Au-LE & $\mathbf{R}_{20^{\circ} \mathrm{C}}(\mathbf{\Omega})$ & Slope $\left(\Omega /{ }^{\circ} \mathrm{C}\right)$ & $\alpha\left({ }^{\circ} \mathrm{C}^{-1}\right)_{\text {ocp }}$ & $\%$ Error of $\alpha$ at each Au-LE \\
\hline 1 & 2.22 & 0.00526 & 0.00237 & 30.37 \\
\hline 2 & 2.04 & 0.00545 & 0.00267 & 21.59 \\
\hline 3 & 2.02 & 0.00494 & 0.00245 & 27.93 \\
\hline 4 & 2.04 & 0.00507 & 0.00248 & 26.92 \\
\hline 5 & 2.04 & 0.00484 & 0.00237 & 30.28 \\
\hline Average & 2.07 & 0.00511 & 0.00247 & \\
\hline Std. Dev. & 0.0841 & 0.000246 & 0.000122 & \\
\hline RSD (\%) & 4.06 & 4.81 & 4.94 & \\
\hline$\%$ Error & - & - & 27.42 & \\
\hline
\end{tabular}

Table S4. Electrical resistivity $\rho(\Omega m)$, of five Au-LE at each heat pulse during OCP temperature calibration. Equation 5 was used to calculate $\rho(\Omega \mathrm{m})$ using the temperature coefficient $\alpha\left(\mathrm{C}^{-1}\right)$ obtained from the same method.

\begin{tabular}{|c|ccccc|c|c|c|}
\hline \multirow{2}{*}{$\begin{array}{c}\text { Power } \\
\text { Step }\end{array}$} & Au-LE 1 & Au-LE 2 & Au-LE 3 & Au-LE 4 & Au-LE 5 & Average & $\begin{array}{c}\text { Std. } \\
\text { Dev. }\end{array}$ & $\begin{array}{c}\text { RSD } \\
(\%)\end{array}$ \\
\cline { 2 - 9 } & $2.451 \mathrm{E}-08$ & $2.451 \mathrm{E}-08$ & $2.451 \mathrm{E}-08$ & $2.449 \mathrm{E}-08$ & $2.448 \mathrm{E}-08$ & $2.45 \mathrm{E}-08$ & $1.35 \mathrm{E}-11$ & 0.06 \\
100 & $2.480 \mathrm{E}-08$ & $2.480 \mathrm{E}-08$ & $2.477 \mathrm{E}-08$ & $2.473 \mathrm{E}-08$ & $2.474 \mathrm{E}-08$ & $2.48 \mathrm{E}-08$ & $3.45 \mathrm{E}-11$ & 0.14 \\
200 & $2.521 \mathrm{E}-08$ & $2.521 \mathrm{E}-08$ & $2.514 \mathrm{E}-08$ & $2.509 \mathrm{E}-08$ & $2.509 \mathrm{E}-08$ & $2.51 \mathrm{E}-08$ & $6.26 \mathrm{E}-11$ & 0.25 \\
300 & $2.574 \mathrm{E}-08$ & $2.574 \mathrm{E}-08$ & $2.557 \mathrm{E}-08$ & $2.553 \mathrm{E}-08$ & $2.549 \mathrm{E}-08$ & $2.56 \mathrm{E}-08$ & $1.20 \mathrm{E}-10$ & 0.47 \\
400 & $2.634 \mathrm{E}-08$ & $2.634 \mathrm{E}-08$ & $2.611 \mathrm{E}-08$ & $2.602 \mathrm{E}-08$ & $2.595 \mathrm{E}-08$ & $2.62 \mathrm{E}-08$ & $1.78 \mathrm{E}-10$ & 0.68 \\
500 & & &
\end{tabular}


Table S5. Electrode resistance of two-point temperature calibration by resistivity method. Resistance at room temperature $\left(23.8^{\circ} \mathrm{C}\right)$ is also provided.

\begin{tabular}{|c|ccccc|c|}
\hline \multirow{2}{*}{ Temperature $\left({ }^{\circ} \mathrm{C}\right)$} & \multicolumn{5}{|c|}{ Electrode Resistance ( $\mathbf{\Omega})$} & \multirow{2}{*}{$\begin{array}{c}\text { Std. Dev. } \\
\text { (between Au-LE) }\end{array}$} \\
\cline { 2 - 6 } & Au-LE 1 & Au-LE 2 & Au-LE 3 & Au-LE 4 & Au-LE 5 & 0.09 \\
\hline $\mathbf{0}$ & 2.27 & 2.09 & 2.07 & 2.08 & 2.09 & 0.10 \\
$\mathbf{1 0 0 . 4}$ & 2.82 & 2.62 & 2.59 & 2.60 & 2.61 & 0.09 \\
$\mathbf{2 3 . 8}$ & 2.41 & 2.23 & 2.20 & 2.22 & 2.22 & \\
\hline
\end{tabular}

Table S6. Temperature coefficient $\alpha$ of two-point temperature calibration by resistivity method. Theoretical value of temperature coefficient for gold metal is $0.0034 \mathrm{C}^{-1}$.

\begin{tabular}{|c|c|c|c|c|}
\hline Au-LE & $\mathbf{R}_{\mathbf{2 0}}{ }^{\circ} \mathbf{C}(\boldsymbol{\Omega})$ & Slope $\left(\mathbf{\Omega} /{ }^{\circ} \mathbf{C}\right)$ & $\mathbf{\alpha}\left({ }^{\circ} \mathbf{C}^{-1}\right)$ & \% Error of $\boldsymbol{\alpha}$ at each Au-LE \\
\hline $\mathbf{1}$ & 2.38 & 0.00547 & 0.00230 & 32.48 \\
$\mathbf{2}$ & 2.20 & 0.00527 & 0.00239 & 29.61 \\
$\mathbf{3}$ & 2.17 & 0.00520 & 0.00239 & 29.65 \\
$\mathbf{4}$ & 2.19 & 0.00517 & 0.00236 & 30.46 \\
$\mathbf{5}$ & 2.19 & 0.00523 & 0.00238 & 29.91 \\
\hline Average & 2.23 & 0.005268 & 0.00237 & \\
Std. Dev. & 0.0871 & 0.0001188 & $4.078 \mathrm{E}-05$ & \\
RSD (\%) & 3.91 & 2.26 & 1.72 & \\
\% Error & - & - & 30.42 & \\
\hline
\end{tabular}

*Two-point temperature calibration by OCP of five heated electrode, not shown in table S6, had a slope of $0.00504 \Omega /{ }^{\circ} \mathrm{C}, \mathrm{R}_{20^{\circ} \mathrm{C}}$ was $2.07 \Omega, \alpha$ equal to 0.00243 and $28.55 \%$ error.

${ }^{* *}$ After Q-test, and Au-LE 1 resistance values were rejected, for the two-point resistive method calibration the slope was $0.00522 \Omega /{ }^{\circ} \mathrm{C}, \mathrm{R}_{20^{\circ} \mathrm{C}}$ was $2.19 \Omega, \alpha$ equal to 0.00239 and $29.80 \%$ error. Two-point OCP calibration the slope was $0.00497 \Omega /{ }^{\circ} \mathrm{C}, \mathrm{R}_{20^{\circ} \mathrm{C}}$ was $2.04 \Omega$, $\alpha$ equal to 0.00244 and $28.27 \%$ error. 
Table S7. Dixon's Q-test of OCP resistance measurements at each power step of five Au-LE. Qexp for Au-LE 1 was higher than the Qtable (99\%) and increased at each power step, therefor Au-LE 1 resistance measurements were rejected for statistical purposes. Qtable, $99 \%$ confident, was 0.821 .

\begin{tabular}{|c|c|}
\hline Power Step & $\mathbf{Q}_{\exp }$ \\
\hline 100 & 0.836 \\
\hline 200 & 0.846 \\
\hline 300 & 0.895 \\
\hline 400 & 0.895 \\
\hline 500 & 0.888 \\
\hline Average & $\mathbf{0 . 8 7 2}$ \\
\hline
\end{tabular}

Table S8. Independent temperature calibration of Au-LE by controlling bulk temperature with ANOVA water bath. Trials were repeated in triplicates for each electrode. Theoretical value of temperature coefficient for gold metal is $0.0034 \mathrm{C}^{-1}$.

\begin{tabular}{|c|ccccc|c|}
\hline \multirow{2}{*}{ Temperature $\left({ }^{\circ} \mathbf{C}\right)$} & \multicolumn{5}{|c|}{ Electrode Resistance ( $\mathbf{\Omega})$} & \multirow{2}{*}{$\begin{array}{c}\text { Std. Dev. } \\
\text { (between Au-LE) }\end{array}$} \\
\cline { 2 - 6 } & Au-LE 1 & Au-LE 2 & Au-LE 3 & Au-LE 4 & Au-LE 5 & 0.0873 \\
\hline $\mathbf{2 0 . 1 7}$ & 2.39 & 2.20 & 2.18 & 2.20 & 2.20 & 0.0898 \\
$\mathbf{2 9 . 7 3}$ & 2.44 & 2.25 & 2.23 & 2.24 & 2.25 & 0.0891 \\
$\mathbf{3 9 . 7 0}$ & 2.50 & 2.31 & 2.29 & 2.31 & 2.30 & 0.0934 \\
$\mathbf{4 9 . 9 3}$ & 2.56 & 2.37 & 2.34 & 2.35 & 2.35 & 0.0930 \\
$\mathbf{5 9 . 3 3}$ & 2.61 & 2.42 & 2.39 & 2.39 & 2.40 & \\
\hline
\end{tabular}


Table S9. Temperature coefficient $\alpha$ of independent calibration by bulk temperature controlling with ANOVA water bath. Theoretical value of temperature coefficient for gold metal is $0.0034 \mathrm{C}^{-1}$.

\begin{tabular}{|c|c|c|c|c|}
\hline Au-LE & $R_{20^{\circ} \mathrm{C}}(\Omega)$ & Slope $\left(\Omega /{ }^{\circ} \mathrm{C}\right)$ & $\alpha\left({ }^{\circ} \mathrm{C}^{-1}\right)$ & $\%$ Error of $\alpha$ at each Au-LE \\
\hline 1 & 2.39 & 0.00558 & 0.00233 & 31.33 \\
\hline 2 & 2.20 & 0.00548 & 0.00249 & 26.85 \\
\hline 3 & 2.18 & 0.00534 & 0.00245 & 27.95 \\
\hline 4 & 2.20 & 0.00504 & 0.00229 & 32.62 \\
\hline 5 & 2.20 & 0.00514 & 0.00234 & 31.28 \\
\hline Average & 2.23 & 0.005316 & 0.00238 & \\
\hline Std. Dev. & 0.0873 & 0.0002260 & 8.397E-05 & \\
\hline RSD (\%) & 3.91 & 4.25 & 3.53 & \\
\hline$\%$ Error & - & - & 30.01 & \\
\hline
\end{tabular}

Table S10. Comparison of temperature coefficient $\alpha$ obtained by OCP and resistivity method, respectively.

\begin{tabular}{|c|c|c|c|}
\hline Method & $\begin{array}{c}\text { Open-Circuit } \\
\text { Potentiometry }\end{array}$ & $\begin{array}{c}\text { Resistivity } \\
\text { (two-point } \\
\text { calibration) }\end{array}$ & $\begin{array}{c}\text { Resistivity } \\
\text { (Bulk temperature } \\
\text { controlled by } \\
\text { ANOVA water } \\
\text { bath) }\end{array}$ \\
\hline Au-LE & \multicolumn{3}{|c|}{$\mathbf{\alpha}\left({ }^{\circ} \mathbf{C}^{-1}\right.$ ) } \\
\hline $\mathbf{1}$ & 0.00237 & 0.00230 & 0.00233 \\
$\mathbf{2}$ & 0.00267 & 0.00239 & 0.00249 \\
$\mathbf{3}$ & 0.00245 & 0.00239 & 0.00245 \\
$\mathbf{4}$ & 0.00248 & 0.00236 & 0.00229 \\
$\mathbf{5}$ & 0.00237 & 0.00238 & 0.00234 \\
\hline Average & 0.00247 & 0.00237 & 0.00238 \\
Std. Dev. & 0.000122 & $4.078 \mathrm{E}-05$ & $8.397 \mathrm{E}-05$ \\
RSD (\%) & 4.94 & 1.72 & 3.53 \\
\% Error & 27.42 & 30.42 & 30.01 \\
\hline
\end{tabular}


Table S11. Values of electrical resistivity $\rho$ at $20{ }^{\circ} \mathrm{C}$ and temperature coefficient $\beta$ of sintered porous bronze alloy made from $89 \% \mathrm{Cu}$ and $11 \% \mathrm{Sn}$ powder reported by Grootenhuis et.al. [31].

\begin{tabular}{|c|c|c|c|c|}
\hline $\begin{array}{c}\text { Density } \\
\left(\mathbf{g} / \mathbf{c m}^{3}\right)\end{array}$ & $\begin{array}{c}\boldsymbol{\rho} \text { at } \mathbf{2 0} \\
\left(\boldsymbol{\mu} \mathbf{\Omega}^{*} \mathbf{C} \mathbf{c m}\right)\end{array}$ & $\boldsymbol{\beta}\left({ }^{\circ} \mathbf{C}^{-1}\right)$ & Grade of alloy & $\begin{array}{c}\text { Particle } \\
\text { diameter }(\mathbf{c m})\end{array}$ \\
\hline 5.50 & 60.1 & 0.00047 & E1 & 0.04000 \\
\hline 5.55 & 81.5 & 0.00057 & $\mathrm{C} 1$ & 0.01275 \\
\hline 5.75 & 52.0 & 0.00053 & D1 & 0.02113 \\
\hline 5.85 & 57.1 & 0.00070 & B1 & 0.00493 \\
\hline 6.30 & 38.5 & 0.00059 & B1 & 0.00493 \\
\hline 6.45 & 33.0 & 0.00061 & A1 & 0.00133 \\
\hline
\end{tabular}


Figure S5. (A) Electrical resistivity $\rho$ and (B) temperature coefficient $\beta$ of sintered porous bronze alloy material made from $89 \% \mathrm{Cu}$ and $11 \% \mathrm{Sn}$ powder by metallurgy methods with different densities. Densities varies according to its particle size diameter. Graphs were plotted using the data set from Table S11.

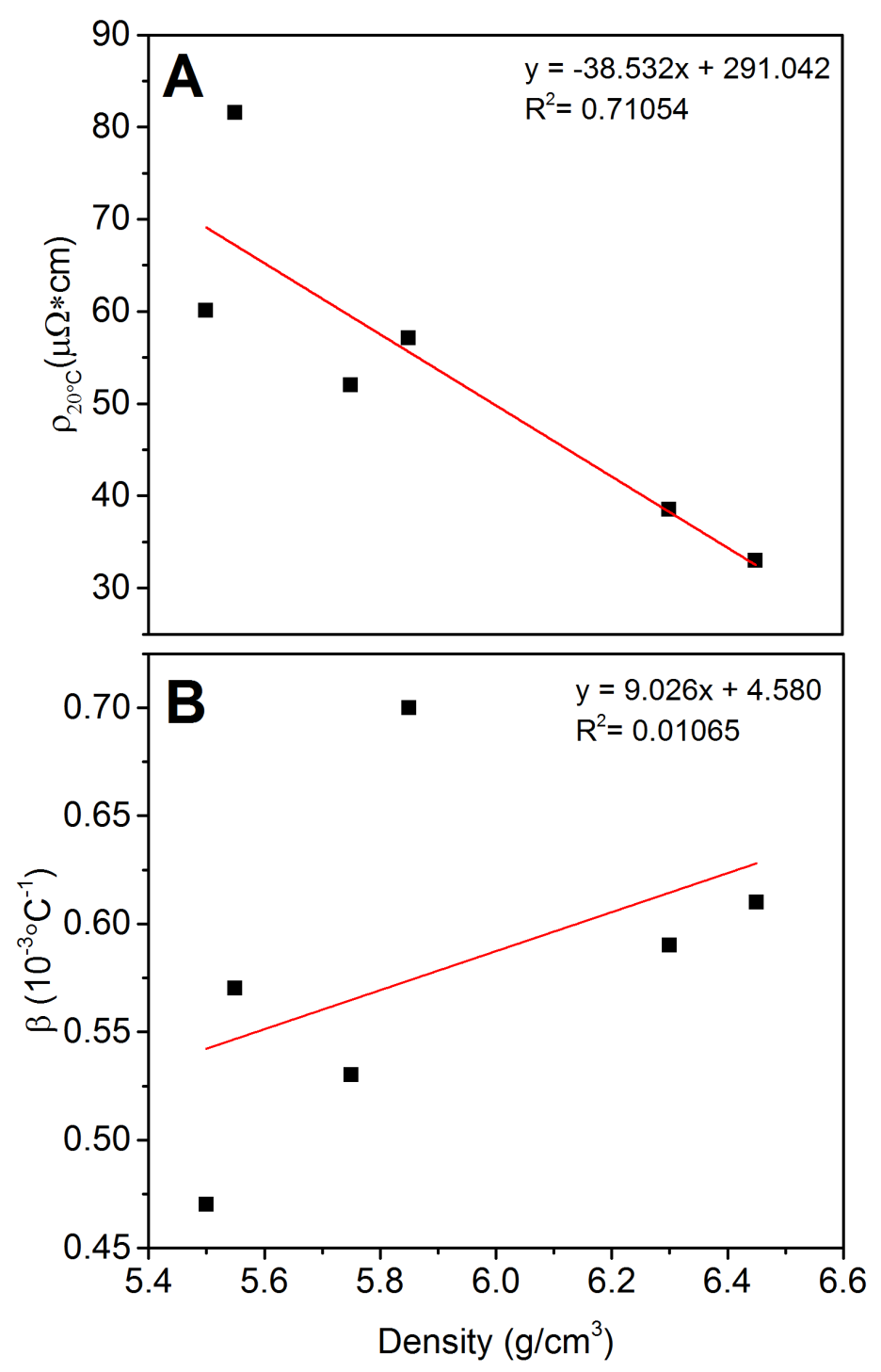


Automatic Temperature Calibration-SI-rev-20190521.pdf (895.42 KiB) view on ChemRxiv • download file 